
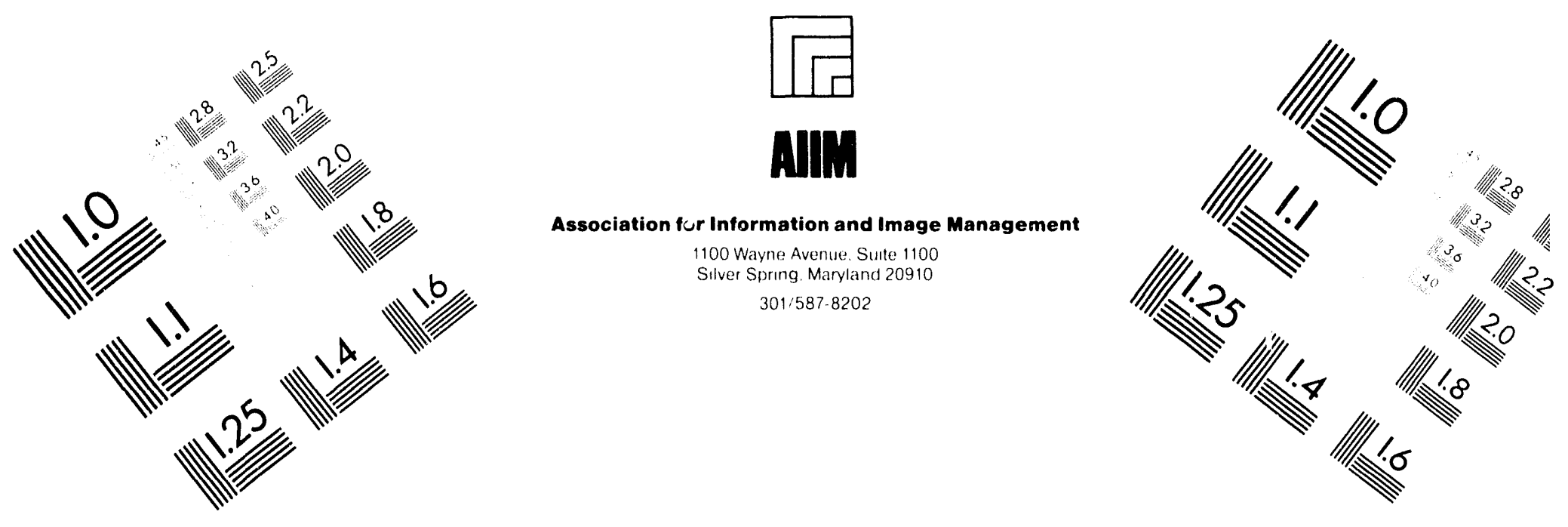

\title{
Centimeter
}

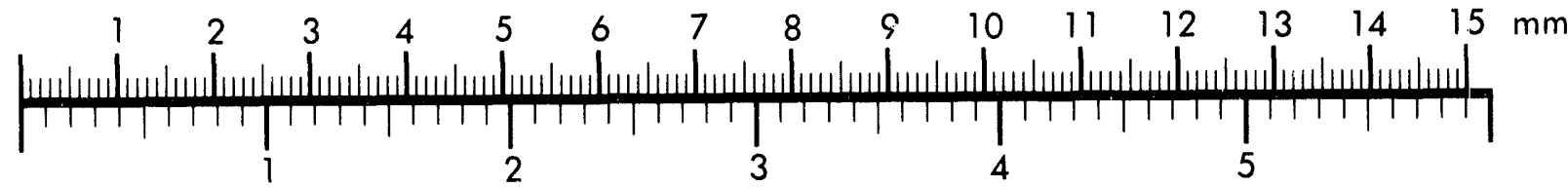

Inches
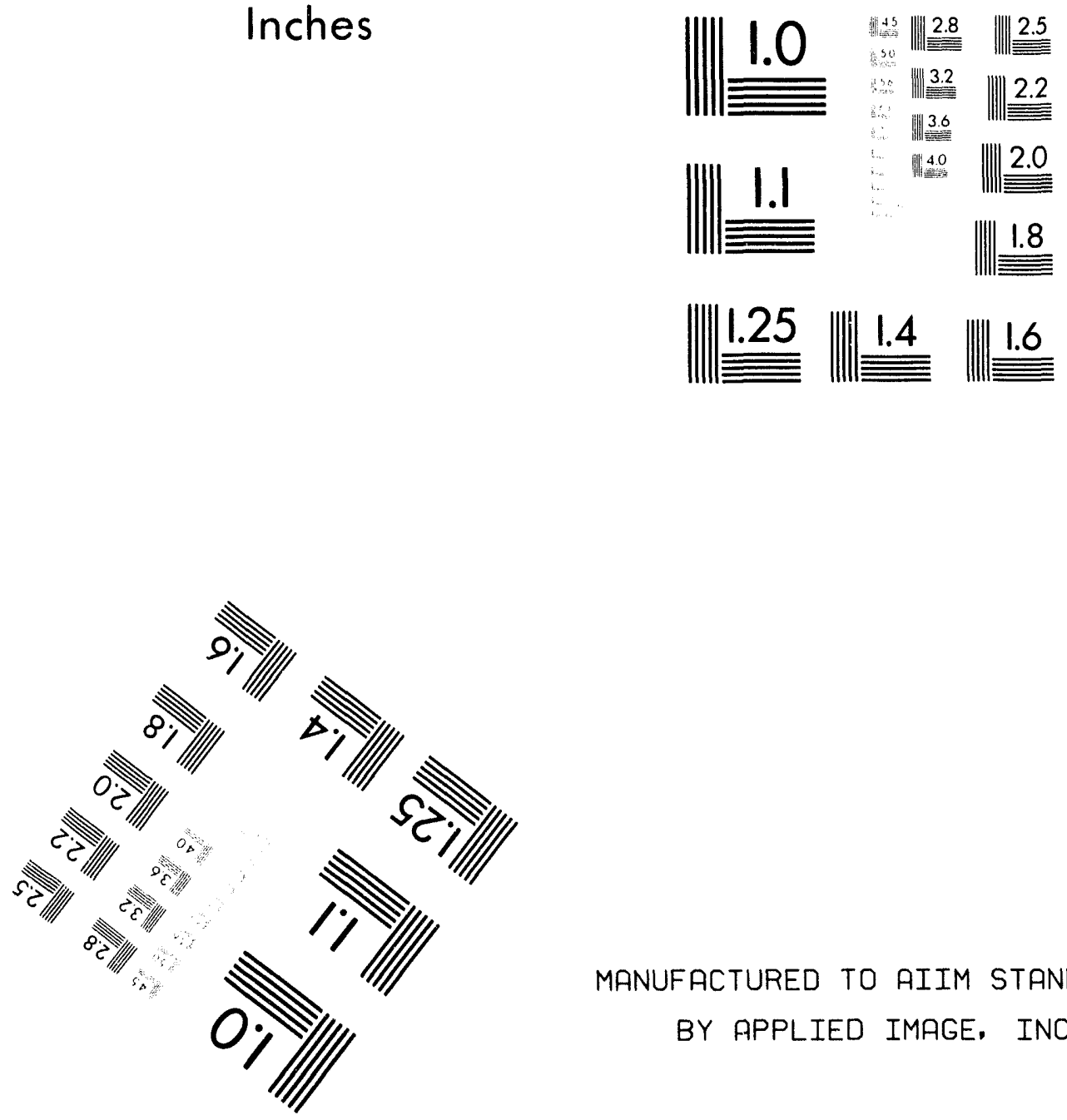

MANUFACTURED TO AIIM STANDARDS

BY APPLIED IMAGE, INC.

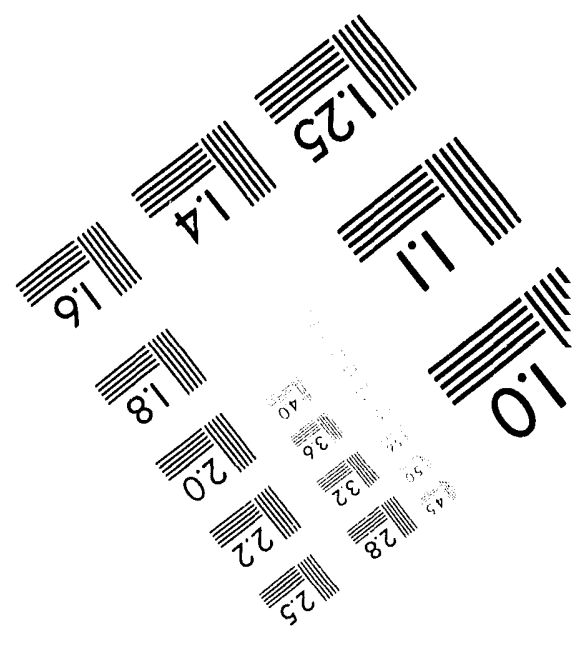



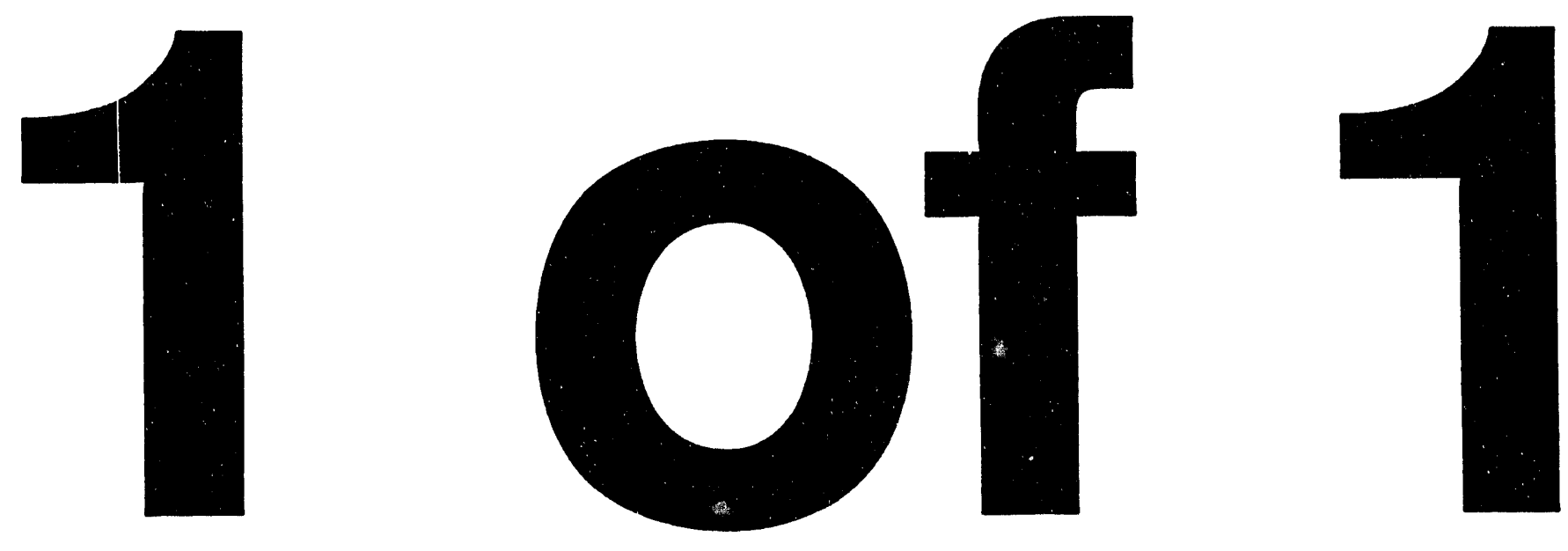
HANFORD ATOMIC PNODUCTB OPERATION - RICHLAND, WAEHINGTON

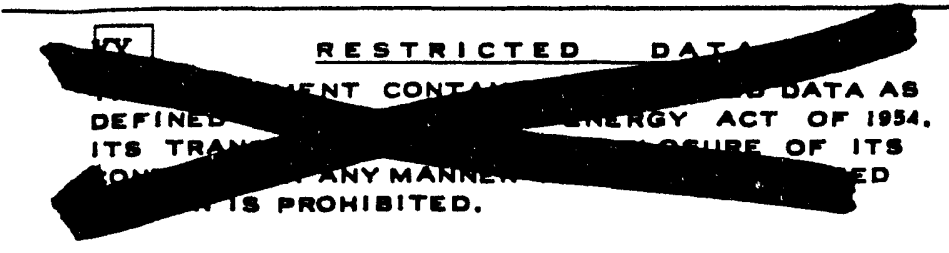

$\square$ OTHER OFFICIAL CLABSIFIED INFORMATION THIS MATERIAL CONTAINS INFORMATION AFFECTING TME NATIONAL DEFENSE OF THE UNITED STATES WITHIN THE MEANING OF THE ESPIONAGE LAWB, TITLE 10, U.S.C., SECS. 793 AND 794, THE TRANSMISSION OR REVELATION OF WHICH IN ANY MANNER TO AN UNAUTHORIZED PERSON IS PROHIBITED BY LAW.
TITLE

\section{DESCRIPTION OF THE NET RETURN OPTIMIZATION COMPUTER PROGRAM - IBM 7090, FORTRAN MONITOR}

\section{AUTHOR}

G. R.Sparks
Qfmiterent P.ES:-:

\section{THIS DOCUMENT OR WHERE AN UNAUTHORIZTHY}

TO IT. WHEM

GUARDE-

CLAR WHILE IT IS YQMU TLES, IT IS Y UJECT AND FROM

UESIDENCE DTAIN THEM TO SION IN INSIBILITY
UTHORIZED PERSO RE. IT IS NOT
RELATED ISSUING MCE PROVIDED BELOW.

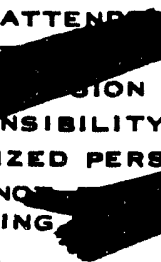
AN APPROVED LOCKF? AND UNTIL YO CRE WITHIN AN
TAINED A SIGNED OT. ITS CONTENTS WITHED BN AROM Rilis: ROUTE TO:

\begin{tabular}{|c|c|c|c|c|c|c|}
\hline ROUTE TO: & PAYROLL NO. & LOCATION & FILES ROUTE & BIGNATURE & AND & DATE \\
\hline L & 12654 & & $6-20-6$ & & & \\
\hline$\therefore$ & $1 \cdot \therefore$ & $=\ldots$ & $\cdots$ & & & \\
\hline
\end{tabular}

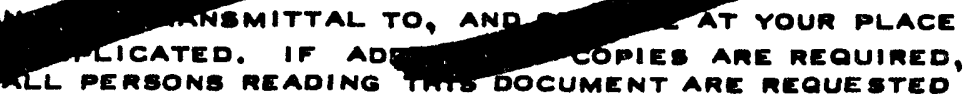

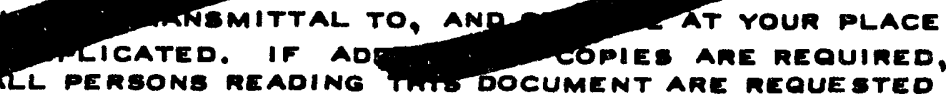




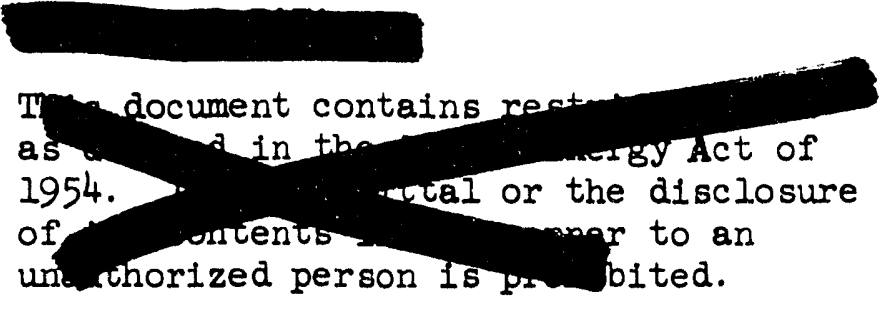

\section{PRELTMTNARY REPORT}

This report was prepared only for use within General Electric Company in the course of work under Atomic Energy Commission Contract AT(45-1)-1350. Any views or opinions expressed in the report are those of the author only.

DISTRIBUTION

1. ER Astley

2. RE Baars

3. CA Bennett

4. $\pi$ Benson

5. DL Condotta

6. BR Cremer

7. EA Eschbach

8. N Fifer

9. NE Fuller

10. SM Graves

11. OH Greager

12. AK Hardin

13. HW Heacock

14. PJ Hollifield

15. CG Hough

16. RD Jensen

17. IW Lang

18. IC Lessor

19. ILT NewelI

20. KW Norwood

21. CF Poor

22. WH Radtke

23. RW Reid

24. DL Renberger

25. SH Small

26. WR Smit

27. GR Sparks

28. HG Spencer

29. DR Stenquist

30. SA Wood

31. JR Young

32. PJ Zimmerman

33. HF Zurh

34. 300 Files

35. Record Center

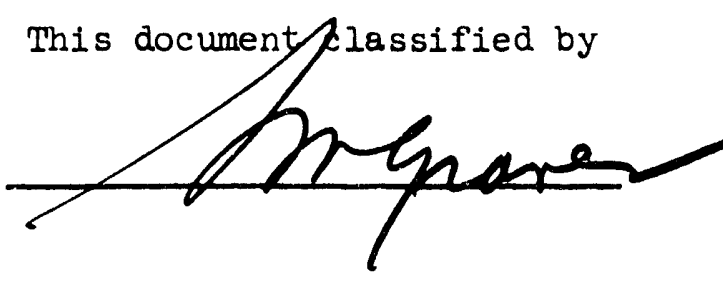

This document consists of

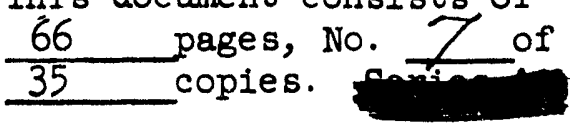

Claseification Cancollod and Changed To

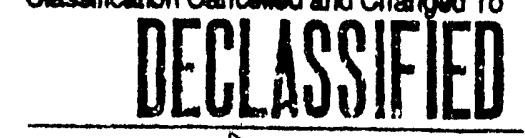

By Authority at

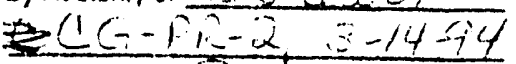

By $C=5$ Surlig 4-1-94

Verifida By DKUtanson, 4.15.94 
DESCRIPTION OF THE NET RETURN IBM 7090, FORTRAN MONITOR

\section{INIRODUCTION}

\section{DECLLSSSFIED}

During the past four years, IBM data processing computers have been utilized to perform countless studies involving the optimization of the HAPO plutonium production complex (HAPO and off-site supporting plants). During this time, three process optimization models have been constructed and associated Fortran programs have been written. The se three are 1) maximum net return, 2) minimum reactor unit cost, and 3) maximum grams. This document will be concerned only with the first program: net return optimization. ${ }^{1}$

In January of 1960, a new program was written for the IBM EDPM 709. 2 This new program incorporated the desirable features of the previous programs and provided additional output data.

During the two years since January, 1960, the net return optimization program has undergone many changes. The se changes have been caused by improvements in the process technology and a major change in the definition of the Pu-240 specification:

It is the purpose of this document to describe the current version of the net return optimization program. (The reader should understand that even as this is being written, charges to the existing program are being contemplated. It is anticipated that a future description will include the se changes.)

\footnotetext{
IMusic, J.F., et al, Reactor Process Optimization, HW-61579, August 17, 1959, secret.

2Turner, R.L., and C.F. Poor, Process Optimization 709 Program, HW-64654, April 6, 1960, Secret.
} 
DISCUSSION

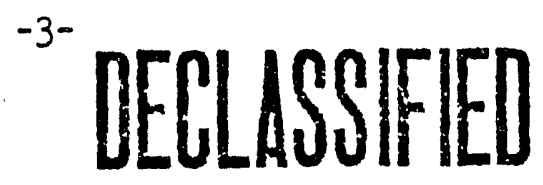

HW -73713

Description of the Program

The description of the net return optimization program is divided into the following sections and appendices:

\section{SECTIONS}
A. Process Optimization
B. Program Utilization
C. Search Routine
D. Definition of Optimum, Ridges, Fixed, Case, set and Run
E. Program Flexibility
F. Program Control
G. Assembling a Set of Input Data
H. Summation Routine
I. Assembling a Run

\section{APFENDICES}
A. Sample Printout Pages
B. Input Data Card Formats
C. Glossary of Input-Output Symbols

A. Process Optimization

The net return optimization computer program is a Fortran system program designed to simulate the physical and economic performance of the HAPO plutonium production complex. Simulation of the process is accomplished by the uss of a mathematical model which describes the plant operation as a function of the plant operating conditions. A conceptual equation describing the ret return model $1 \mathrm{~s}$ : 


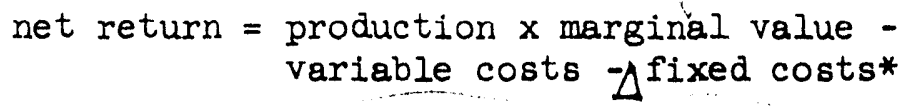

This program can be used in two basically different ways:

1. A set of operating conditions can be specified and the program will determine the associated plutonium production, net return, operating costs, and other dependent variables.

2. A marginal value (sales prices of plutonium) can be specified and the program will determine the operating conditions which will yield the maximum net return.

The general technique used in the latter application is one of successive iteration of reactor powers and fuel exposures until the combination is reached which produces the optimum performance of the complex.

\section{B. Program Utilization}

The use of this program falls into two general categories: 1) the evaluation of process parameter changes, and 2) forecasts and operating plan recommendations.

The evaluation of varying one or more of the process variables can be carried out to study such problems as the optimum charge length, incentive for fuel performance improvement, total reactor control, project justifications, etc.

Plant power level and goal exposure recommendations made by Process Engineering Unit are based upon results emanating from this program. Process Analysis Unit uses the program in the preparation of two and

* In the program, net return plus fixed costs are denoted by the quantity $\mathbf{Z}$. ZMAX is the maximum $\mathrm{Z}$ and represents the condition of maximum net return plus fixed costs. 
five-year power level forecasts and optimum plant goal exposure recommendations.

Process Technology Sub-Section administers and maintains the program and serves various customers (Manufacturing Section, IPD; and FPD) by either performing studies dependent upon the program or offering to assist other components in adapting the program to their specific needs.

\section{Search Routine}

The heart of this program is the optimization search routine which varies $P$ (power), BMI, EME, EMS (three metal type exposures) until $Z$ (net return plus fixed costs) is a maximum. To describe this routine in infinite detail would be a disservice to the reader, but the general philosophy is important to a basic understanding of the program.

Think of a mountain where the north-south direction is called $P$ and the east-west direction is BMI and the peak of the mountain is our goal, $\mathrm{z}$ Max. Starting at a point on the mountain (we are at a three dimensional intercept where $P$, EMI, and $\mathrm{z}$ have unique values), we walk up the mountain on a constant EMI line. $\mathrm{P}$ and $\mathrm{Z}$ will increase as we walk unless we are very lucky and have chanced upon the EMI line that will take us directly to the peak. We will eventually reach a crest on the side where $\mathbf{Z}$ is maximum then start down the other side where $\mathbf{Z}$ now becomes less than the crest $\mathbf{z}$. Now, we back up to the crest $\mathbf{z}$ and start walking at a right angle up the mountain on a constant $P$ line until we hit another crest. This process will be repeated until we find ourselves at the peak, or $\mathrm{z}$ max--our goal. At this point on the mountain, we can see what $P$ and IMI lines we are on as well as the value of the maximum $\mathbf{Z}$. 
This is a rather simple analogy of the net return optimization concept since it deals with only two variables, $P$ and EMI, and the program model is based on four variables.

The foregoing describes what we call the optimum search routine. A specialized search routine is called the "ridge" and gets its name from the fact that it is designed to find the crest $Z$ 's for a fixed schedule of $P$ or EMI lines.

D. Definition of Optimum, Ridges, Fixed, Case, Set, and Run

The following words are used throughout the discussion and have special meanings as follows:

"Optimum" refers to the results obtalned when the power level (P) and the gool exposures of the three metal types (EMI, EME, BMS) are varied by the search routine until the combination of power level and goal exposures result in the maximum net return plus fixed cost (z) for the given set of input data.

"Ridges" refers to the results obtained when the goal exposures of metal type I (EMI) is held constant at pre-set values, and the power level ( $P$ ) and the remaining two metal type goal exposures (EME, EMS) are allowed to vary until the maximum $\mathrm{Z}$ is obtained with the restraint on metal type 1 goal exposure. Nine cases of the above type are calculated with metal type I (EMI) goal exposure fixed at $200 \mathrm{MWD} / \mathrm{T}$ through $1000 \mathrm{MWD} / \mathrm{T}$ at intervals of $100 \mathrm{MWD} / \mathrm{T}$.

Eleven cases are also calculated for determining the optimum goal exposures of the three metal types (RMI, EME, EMS) to give maximum $\mathbf{z}$ when the tube power $(P)$ is held constant. The tube powers at which the above calculations are made are fixed at $1.0 \mathrm{MW}$ through $2.0 \mathrm{MW}$ at intervals of $0.1 \mathrm{MW}$. 


\section{- DECLLSSFFIED}

With the results of the above type of calculations, effects on metil throughput, production losses, and costs can be evaluated for varying exposure and power conditions.

"Fixed" refers to the type of cases where the power level (P) and the goal exposures of the three metal types (EMI, EME, EMS) are fixed and are submitted as input data (one card per case). The program does not go through the search routine, but calculates the standard output directly.

"Case" refers to the calculation and printout of a standard output. One or more cases can be calculated from one set of input data, each case being given a number in the order of its preparation for printout. For example, from one set of input data: one optimum case, 20 ridge cases, and up to 279 fixed cases* may be prepared.

"Set" refers to one set of input data, which may consist of up to five different groups of input data cards. For example, if an optimum case with a bulk temperature loss schedule is to be salculated, the input data set would consist of two groups of cards: the main group (cards 1-11) and the auxiliary loss-bulk temperature group (cards 12-13).

"Run" refers to one or more sets of input data which will be entered to Electronic Data Processjng Operation (EDPO) f'or Fortran Munitor processing. One or more runs may be entered at a time, but each run will be accompanied by the customary binary deck and identity cards. A run should not exceed 300 cases.*

E. Program Flexibility

The net return optimization program flexibility allows us to obtain

*The restriction on total cases for one run is explained in Summation Routine. 
several types of output data from one set of input data. By the use of various controls (described in Program Control), we san calculate an optimum, a ridge, or a number of fixed coses, or any combination of these types of output. We can also calculate these same types of cases with or without auxiliary losses. These auxiliary losses may be used as a schedule of losses or as a cut-off routine to suspend calculation when a certain value associated with the auxiliary loss is reached. We can also sum the significant output values of up to nine cases at a time for an unlimited combination of cases.

\section{F. Program Control}

There are several ways to control the flow of data calculations in a program. The net return optimization program uses three: 1) control parameters which indicate to the program (a) the type of output cases to caiculate, and (b) the type of input data to be read-in to calculate the cases; 2) the order of the input data cards; and 3) a blank card used to terminate the calculation of fixed cases.

\section{(1) Control Parameters}

The control parameters associated with the ordering of an input data set are described in Assembling a Set of Input Data which follows. These control parameters (I4, I, L7, L8, L9) are specifically associated with controlling the reading-in of input data groups and performing calculations for individual sets of input data.

The control parameter ( 120 , Card A) associated with the summation routine is described in Assembling a Run and Summation Routine sections of this document.

The remaining card I control parameters (L2, L3) do not control 
input data. These control parameters indicate whether an optimum case (I2) will be calculated and/or a ridge (L3) will be calculated for a set of input data.

A similar control (It) Indicates whether fixed case(s) will be calculated, and has been treated as part of the first group because It also controls the reading-in of input data.

(2) order of Input Data Cards

As stated before, the order of the deck of input data cases for a run is important. The input data cards necessary to make the required calculations must be read into the system when they are required and in the order required. The proper ordering of a set and a run are described in the following sections: Assembling a set of Input Data and Assembling a Run.

\section{(3) Blank Card}

The blank card is used to tell the program that, no more fixed case cards are to be read-in for that set of input data.

F. Assembling a Set of Input Data

As defined earlier, a set of input data may include from one to five groups of input data cards. The number of groups will be determined by the type of study being performed. The program has been designed to read-in only the input data groups required for the study. The order in which the se groups are read-in is fixed:

$\begin{array}{cl}\text { Order } & \text { Group } \\ 1 & \text { Main (cards 1-11) } \\ 2 & \begin{array}{l}\text { Auxiliary 10ss-bulk temperature } \\ \text { (cards 12, 13) }\end{array} \\ 3 & \begin{array}{l}\text { Auxiliary 10ss-production efficiency } \\ \text { (cards 14-16) }\end{array}\end{array}$


Order $\quad$ Group

$4 \quad$ Auxiliary loss-total control (cards 17, 18)

5

Fixed case (card 19) (one card for each case, terminated by a blank card)

The method of indicating which group of a set are to be read-in 18 a function of the program control parameters: I4, I, I7, I8, IO.

The main group (cards $1-11$ ) will always be read-1n.

If the auxiliary 10ss-bulk temperature group (cards 12, 13) are tc read-in, they will follow immediately after the main group and I and $I 7$ will be set equal to 2 in card 1 . If the cards are not to be read-1n, I7 will be set to 0 and cards 12, 13 will not be Included in the set. If the auxillary 108s-production efficlency group (cards 14-16) are to be read-in, they will follow in order. I and 19 will be set to 2 in card 1. If the cards are not to be read-1n, $L 9$ will be set to 0 and cards 14-16 will not be included in the set.

If the auxiliary loss-total control group (cards 17, 18) are to be read-in, they follow in order. I and $I 8$ will be set to 2 in card 1 . If the cards are not to be read-in, 18 will be set to 0 and cards 17, 18 will not be included in the set.

If fixed case group (card 19) $\operatorname{card}(8)$ are to be read-in, they will follow in order. It will be set to 2 in card 1 . To terminate the fixed case group, a blank card follows the last card 19. If the card(s) are not to be read-1n, It will be set to 0 and the $\operatorname{card}(8)$ will not be included in the set.

This completes a set of input data. The method of assemblying a number of sets into a run is explained in a following section. 
H. Summation Routine

The Pu-240 specification caused the 8 ummation routine to be included in the current version of the net return optimization program. Prior to its inclusion; the sumation of selected case output values was done by hand.

As each case is calculated, the case number identification starting with $I$ and increasing by one for each succeeding case 18 assigmed. Certain output quantities of the case (see Appendix A for complete list) are stored away at the time of calculation into a series of 300-unit single-dimension arrays. Consequently, no run should ever exceed 300 cases.

After all of the cases in a run have been calculated, the sumation of these quantities for selected cases (up to nine cases at a time) may be accomplished by the use of pairs of card $A$ and card B.*

When card $\Lambda$ is read, the program reads the card as if it were card 1 of a new set of input data. A test is performed on the 120 quantity to determine whether it is card $A$ or card 1 . If 120 is 0 , it is card 1 . If I20 is 2 , it is card $A$.

Card $B$, which always follows card $A$, * contains the case numbers of the cases to be summed (N1-N9), and the total number of cases (NC) on the card. One or more cases (up to nine) comprise a sumation and any number of summations can be made.

Experience has taught us to layout a visual chart of the case numbers and their unique identification to aid in preparing the card B's and as a quick reference to the summation outputs. For example: case 38 is B reactor, $10 \mathrm{C}$ inlet, 25 dollar $\mathrm{Pu}$, etc.

*In the future, only one card $A$ will be required to precede all card $B^{\prime} B$. 
I. Assembling a Run

\section{"WEELLSSIFIED \\ HW -73713}

As defined earlier, a run is a grouping of one or more input data sets. To "make a run," all input dats sets are combined, one arter the other, into an input deck. The input data deck follows the binary deck, which follows the identification card. If sumation output is desired, the card A, card B groups must follow the last set of input data in the run.*

Since the inception of the Monitor, there 18 no need to terminate the program by a blank card. The blank card is still required to terminate the fixed case calculations of each set of input data when flxed cases are to be calculated.

If the summation routine will be used, it is important to be cognizant of the order in which the input data sets are arranged. Remembering that the sunmation routine sums cases by case number identification, the orderIng of the input data sets and the number of cases, which will be outputed for each set of Input data, must be kept in mind when preparing the CNRD B list of cases to be summed.

There is a limit to the number of cases which can be calculated in a run. This number is 300 and is dictated by the sumation routine. If more than 300 cases are required at one time, break the number up into less than 300 case groups and process these groups as individual runs at the same time. This will require extra copies of the binary deck and identification card.

The following page graphically describes the assembly of a run.

*In the future, only one card A will be used, followed by all card B's. 


\section{EXAMPLE OF TYPICAL RUN ASSEMBLY}

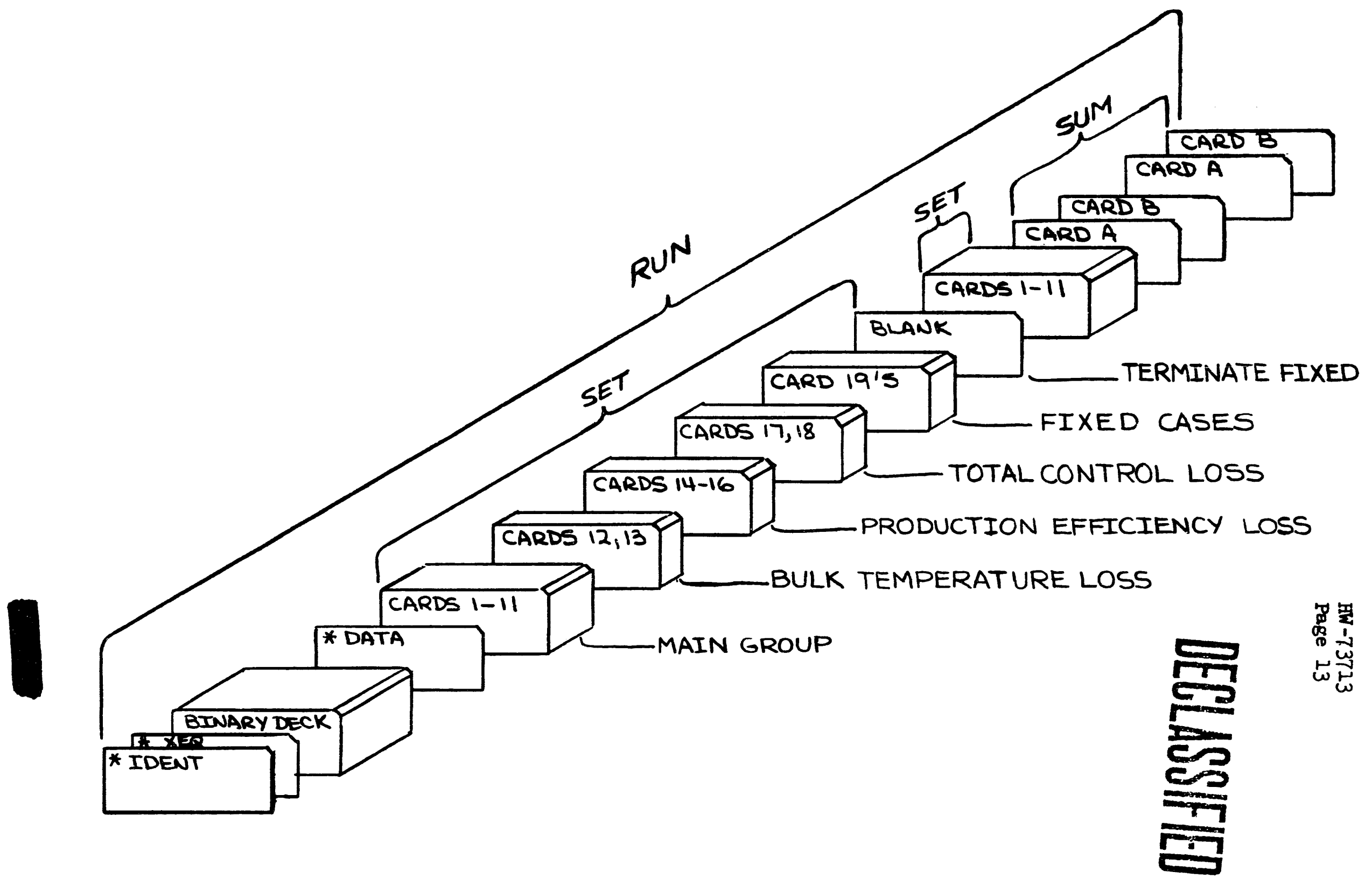




\section{APPENDIX A \\ SAMPIB PRINTOUT PAGBS

The sample pages which follow are representative of one type of program flexibility only. The following notes have been generalized to fit all possible combinations.

\section{First Sample Page}

1. A set of input data will bo printed out under the heading, let Return Optimization - Input Data. Bach pair of lines represents an input data card: the first line indicating the Input data symbol (see Appendix C for definition of symbols) and the quantity of each item drectly below on the second line.

2. Imediately following the printout of input data, one of three case type headings will be shown: Optimum Parameters, Ridges, or Fixed Points. Following Fixed Points, a pair of lines will identify the input data values for card 19. These two lines will appear prior to the output for subsequent fixed cases.

3. Following the case type heading will be the case number 1dentification: Case Number - Xax. The case number starts at I for each run and continues in numerical order $(2,3,4 \ldots)$ up to 300 for each run. The case number is used in the Summation Routine.

4. Following the case number is the standard case output consisting of two pairs of lines (a few input quantities are repeated for convenience and a block of five lines of calculated values). The symbol of the quantities (see Appendix C for definitions) appear directly above the quantities. The block of four quantity lines represent the values for the three metal types $(I, E, S)$ and the toal value (TOT) of the three metal types for each 
of the major column headings, e.g., $\mathrm{CD}(I)$ is the charge-dlscharge loss in days per day of metal type 1.

5. The values printed out in the standard output represent the final or maximum $\mathrm{Z}$ calculated from the input data. In the process of finding the maximum 2 , the program search routine may have calculated several hundred separate $\mathrm{Z}^{\prime} \mathrm{s}$.

\section{Second Sample Page}

6. Each summation will be printed out on a separate page with the heading Summation by Case Number.

7. A pair of Iines Identify the input data values of card B (see Appendix C for definition of symbols). A block of five lines represents the summation values of the cases summated. The same convention as used above, in note 4, describes the block. 
:HET RETURR: OPTINIZATIION - INPUT DATA

$11 \angle 2 \quad 13 L 4 \quad 1 \angle 7 L 8 L 9 L 14 L 15 \quad A 16 \quad A 17 \quad A 18 \quad A 19 L 20$

$2-C-023-C-0-C-0-0 .-0 .-0 .-0$.

$\begin{array}{llllll}\text { ATI CII CTI } & \text { OTI } & \text { A24I } & \text { B24I }\end{array}$

C.S5S4SE OO $0.15256 E-03 \quad 0.14687 E-07 \quad 0.20400 E-00 \quad 124.44 \quad 0.02389$

ITE DTE CTE DTE D A24E R24E

$.79470 E$ CO $0.14637 E-03 \quad 0.131$ COE-07-0. 128.450 .02303

ATS ETS CTS OTS A24S B24S

C.733ESE CO C.149E4E-03 $0.13755 E-07-0 . \quad 124.610 .02388$

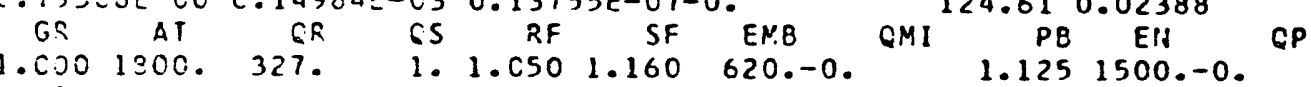

AI AF AS ELN ECI NQXI EQE NQXE EQS NEXS

$\begin{array}{ccccccc}0.500 & 0.150 & 0.005 & 24.0 & 0.057-39 & 0.507-39 & 0.132-39\end{array}$

$X P I X T 1$ XEI XPE XTE XEE XPS XTS XES TFI TFE TFS

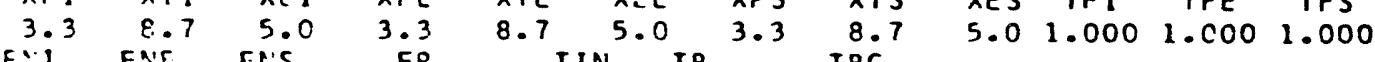

F.' FNE FI.S FR TIN TB TBC

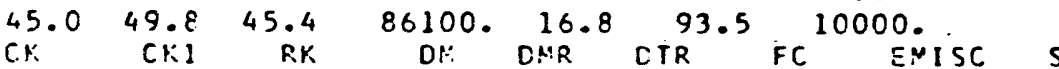

1.200 C.0OC3C $1.180 \quad 30.0 \quad 30.0 \quad 24.0 \quad 34502.0 .140 \quad 0.135$

OU EI CE BS EYCI ENCE ENCS

$5=. O C \quad 5.75 \quad 13.32 \quad 13.32 \quad 4045.00 \quad 3735.00 \quad 3785.00$

TTI TIE TTS CORI CCRE CCRS COLIVE CCLENE CDLSNE

S.17C $11.059 \quad 8.743 \quad 400.0 .400 .0 \quad 400.0 \quad 1.100 \quad 1.100 \quad 1.100$

CPTIRUIM PARAYETERS

CASE I.UREREP- 41

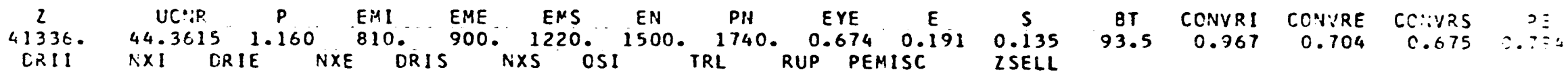

$\begin{array}{lllllllllll}3.81012 & 38 & 0.11089 & 38 & 4.45332 & 36 & 5.352 & 0.031 & 0.022 & 0.111 & 31846\end{array}$

$\begin{array}{lcccccccc} & C D & R L & C 0 N 24 & T P & B O C & \text { TPC } & \text { AVIN } & \text { PMWO } \\ 1 & C .029 & 0.017 & 0.0563 & 1.149 & 8776.08 & 4646.68 & 14.912 & 930.49\end{array}$

$\begin{array}{lllllllll}I & C .029 & 0.017 & 0.0563 & 1.149 & 8776.08 & 4646.68 & 14.912 & 930.49 \\ E & 0.009 & 0.004 & 0.0603 & 0.294 & 2479.35 & 1111.88 & 19.293 & 264.3\end{array}$

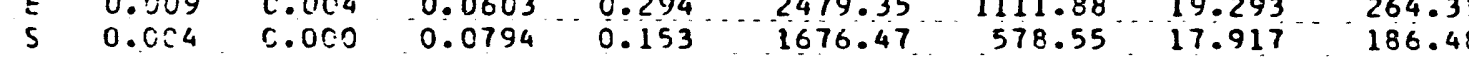

TCT $0.042 \quad 0.022 \quad 0.0599 \quad 1.595 \quad 12931.90 \quad 6337.11 \quad 15.897 \quad 1381.35$

GRM24 P.GR

$40.01 \quad 710.29$

$11.23 \quad 186.14$

$\begin{array}{rr}9.39 & 125.86 \\ 61.23 & 1022.27\end{array}$

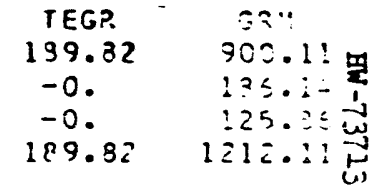


SÜMMATION BY CASÉ NUMMÉR

$\begin{array}{rrrrrrrrrr}N C & N 1 & N 2 & N 3 & N 4 & N 5 & N 6 & N 7 & N 8 & N 9 \\ 8 & 1 & 9 & 25 & 33 & 49 & 4 & 17 & 41 & -0\end{array}$

\begin{tabular}{|c|c|c|c|c|c|c|c|c|}
\hline $\begin{array}{c}1 \\
E \\
S \\
T C T\end{array}$ & $\begin{array}{c}\text { SRCR } \\
9999.64 \\
1574.60 \\
491.80 \\
12066.04\end{array}$ & $\begin{array}{c}\text { STEGR } \\
139.82 \\
0 . \\
0 . \\
189.82\end{array}$ & $\begin{array}{r}\text { SGRM } \\
10189.46 \\
1574.60 \\
491.80 \\
12255.86\end{array}$ & $\begin{array}{r}\text { SGR24 } \\
616.97 \\
87.00 \\
34.32 \\
738.29\end{array}$ & $\begin{array}{r}\text { SBOC } \\
87256.06 \\
20393.16 \\
4832.36 \\
112481.58\end{array}$ & $\begin{array}{r}5 T P C \\
35216.61 \\
9830.58 \\
1780.77 \\
46827.96\end{array}$ & $\begin{array}{r}\text { STP } \\
16.090 \\
2.597 \\
0.740 \\
19.428\end{array}$ & $\begin{array}{l}S C 024 \\
0.0617 \\
0.0553 \\
0.0698 \\
0.0612\end{array}$ \\
\hline
\end{tabular}

t

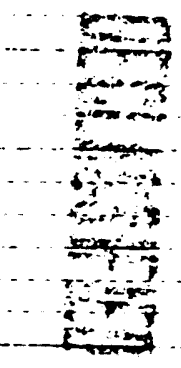




\section{APPENDIX B}

\section{INFUT DATA CARD FORMATS}

The four pages of input data formats which follow represent six groups

of input data cards and are described in the following notes.

1. As explained in Preparation of Input Data, the types of case(s) to be calculated will dictate the number and arrangement of the cards for each set of input cards.

2. The designation for each card group is given as a main heading and are as follows:

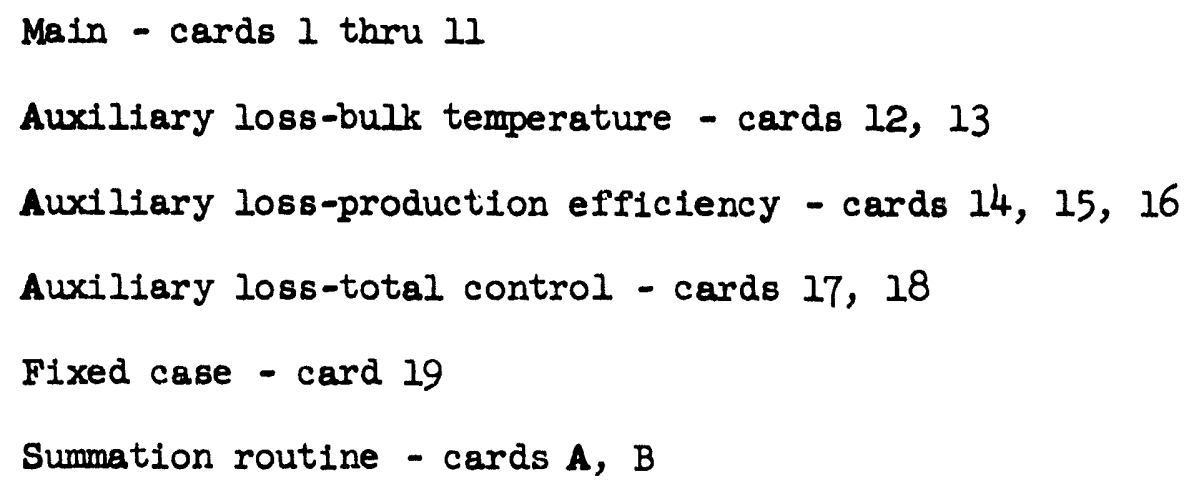

3. Within each group, each card is identified on the right side by its number or letter.

4. Each card is described by three horizontal lines and a group of vertical Iines as follows: the vertical lines indicate the field size of each input data quantity, the first horizontal line describes the symbol names of the input data quantities (see Appendix C for definition of symbols), the second horizontal line indicates the decimal point position of $\mathbf{E}$ and F type formats and the usual magnitude ( $X^{\prime} s$ ) of the quantities, the third horizontal line shows the standard Fortran format identification for each Input data.

5. The same Fortran formats are used for reading-in and writing-out. 
6. I-tjpe formats are usea for integers and care must be used in rightadjusting the integer number within the data field.

7. E-type formats are used for decimel numbers with the powers of ten convention. The power of ten (signed) following the E. For example, $1.384 \times 10^{-37}$ with a format of E9.3 would be $1.334 \mathrm{E}-37$. The "9" refers to the field size and the " 3 " refers to the number of places to the right of the decimal point.

8. F-type formats are used for declmal numbers. For example, 930.7334 with a format of F8.4 would be 930.7834 . The " 8 " refers to the fiela size and the "4" refers to the number of places to the right of the decimal.

9. For a more complete definition of Fortran format rules see IBM Reference ManuaI C28-6054-2, 709/7090 Fortran Programing System. 


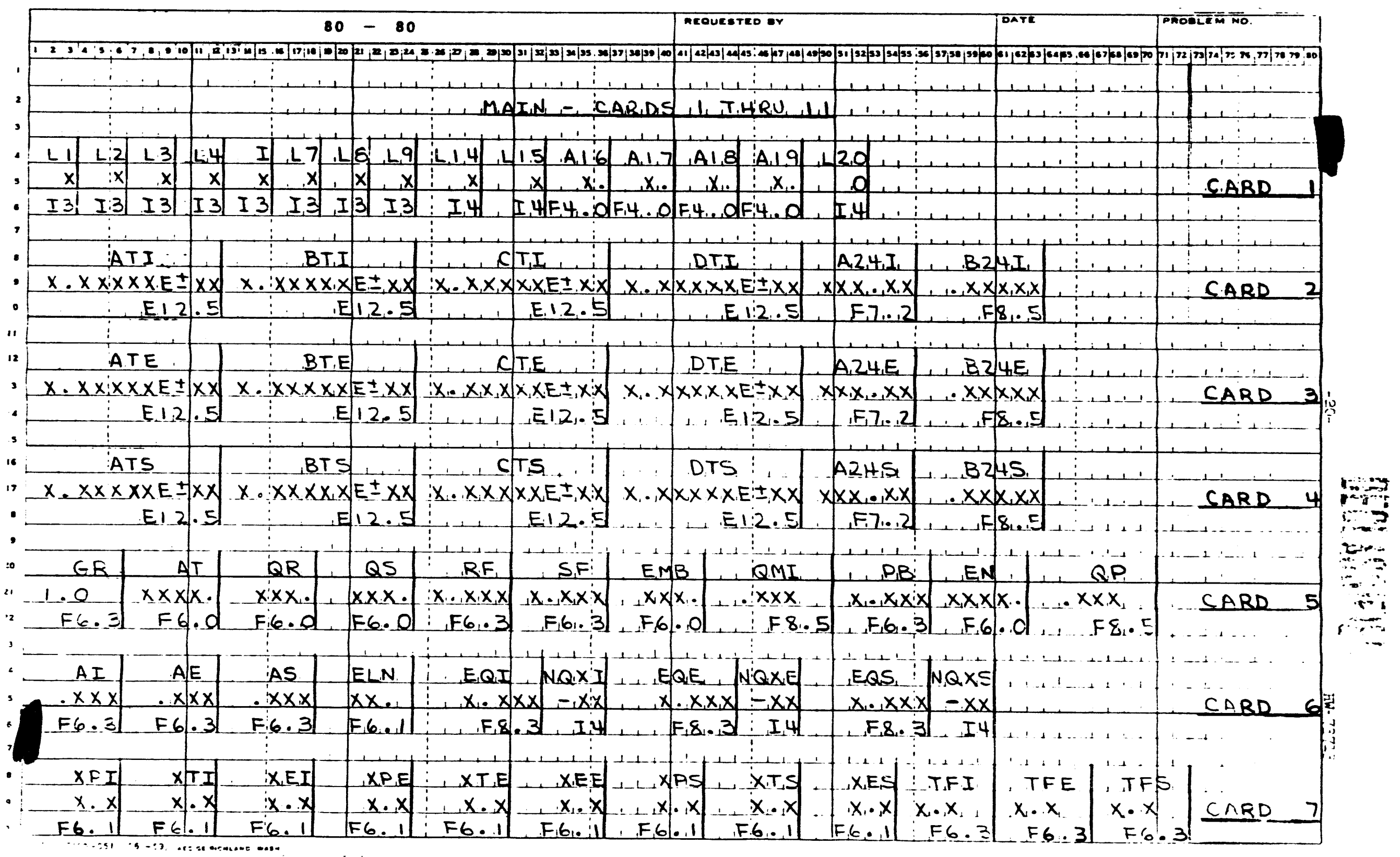




\section{DECLLSSFFIED}

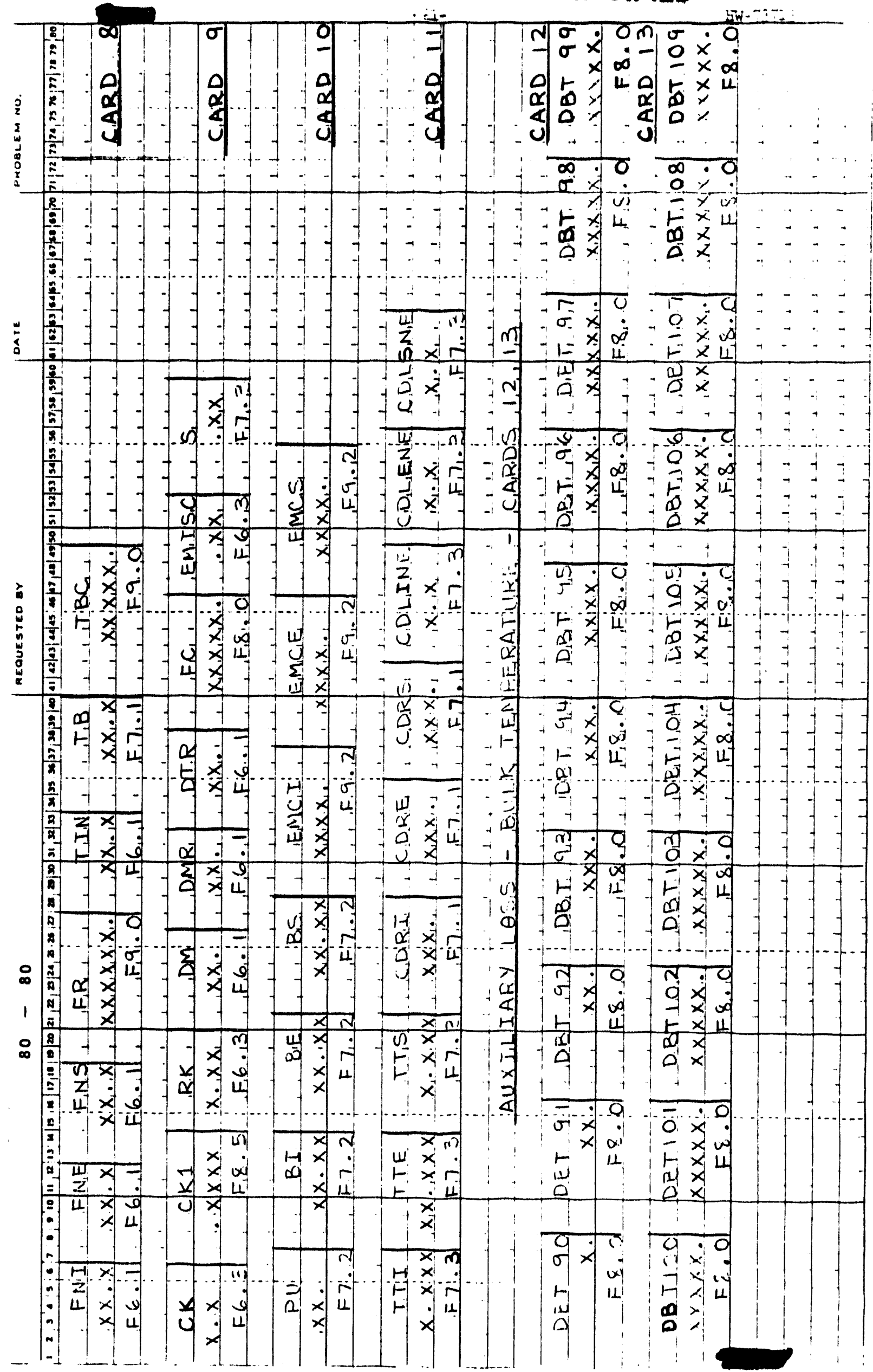


$80-80$

REQuested or

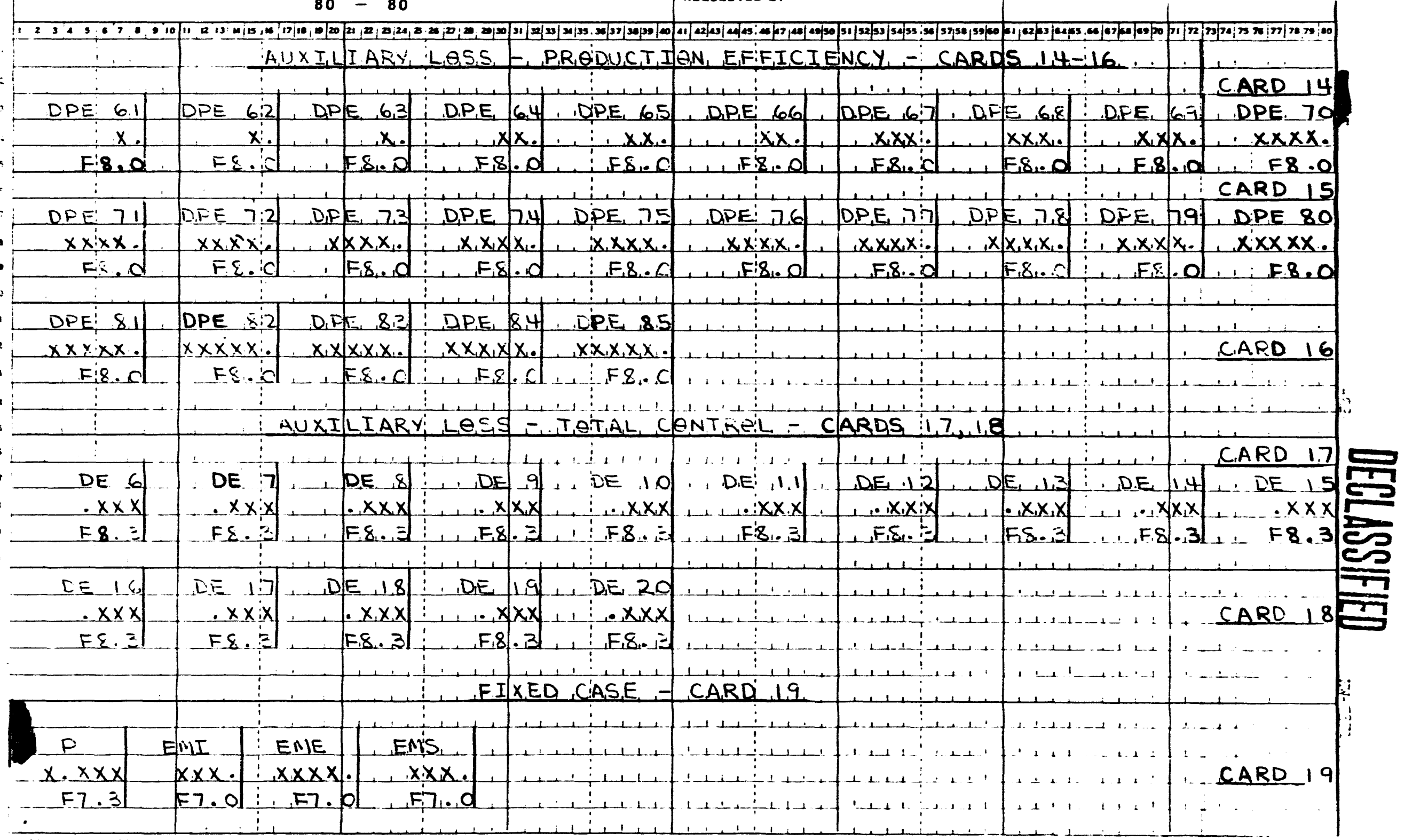




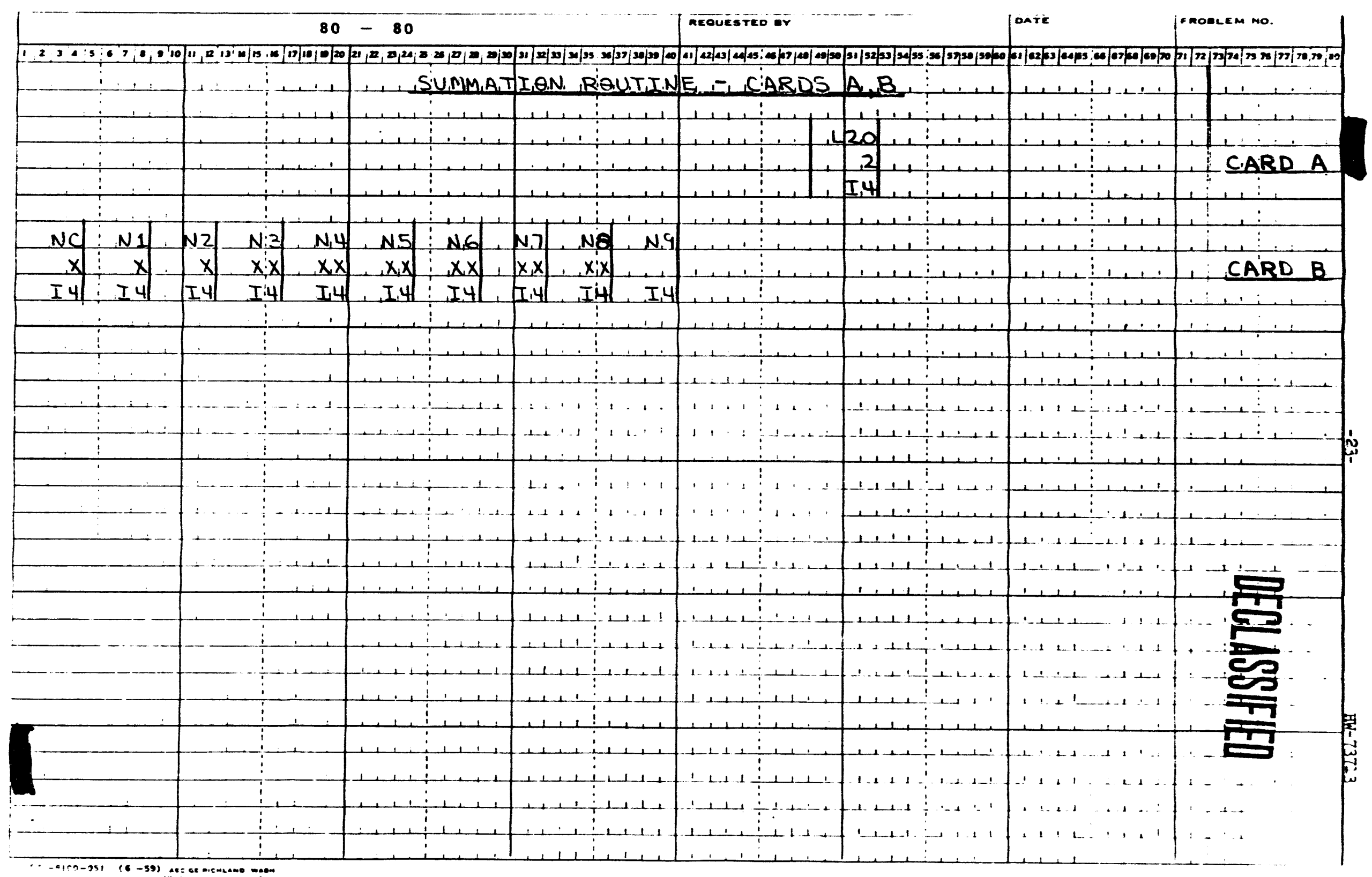




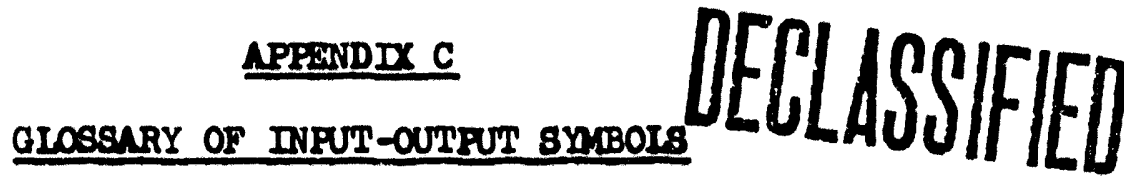

In the following definitions of the input and output printout symbols, several conventions have been used.

1. Groups of symbols ending in I, B, and $\mathbf{S}$ refer to the three metal groups, respectively. Originali.y, these symbols represented: Ifr natural, Iss enriched, and Solid natural metal.

2. Groups of symbols which are subscripted (I), (B), (B), and (TOT) refer to the output section of the printout where the data 18 presented in block form (see sample printout) with the major designation appearing at the top of the column and the subscripted designations appearing only once on the left side of the columns. For example, $\mathrm{CD}(I)$ refors to the calculation of $\mathrm{CDI}, \mathrm{CD}(\mathrm{E})$ refers to $\mathrm{CDE}, \mathrm{CD}(\mathrm{S})$ refers to $\mathrm{CDs}$, and $\mathrm{CD}(\mathrm{TOT})$ refers to $\mathrm{CDT}$.

3. In "Origin" equations used in the program, notice that wherever the heat split of the first metal type (formerly I) is used, the term zhe is used instead. This obvious substitution is a result of certaln Foritran programing rules.

4. It is expected that this glossary will be used to 1dentify the input and output data, the origin of the data (input or calculated), and the units of the data. 


\section{$\underline{16}$}

\section{Defintion}

\section{DECLLSSIFIED}

Constant by which the dally values for the first optimum case are multiplied prior to accumulation.

NOIE: This part of the program will be removed in the future.

Unit

None

Origin

Input data.

Al7

Definition

Constant by which the daily values for succeeding cases are multiplied prior to accumulation.

NOTE: This part of the program will be removed in the future.

Unit

None

Origin

Input data.

118

\section{Definition}

Constant similar to Al6 for fixed cases.

NOWE: This part of the program will be removed in the future.

Unit

None 
Origin

Input data.

$\underline{119}$

Definition

Constant similar to $A 17$ for fixed cases.

NOTE: This part of the program will be removed in the future.

Unit

None

Origin

Input data.

A24I, A24E, A24S

Definition

One of the Pu-240 conversion ratio constants of the three metal types.

Unit

None

Origin

Input data.

$A I, A E, A S$

Definition

Ratio of the tube metal performance index to the reactor metal performance index of the three metal types.

Unit

None 
Origin

Input data.

AT

Definition

The number of active tubes.

Unit

Tubes

Origin

Input data.

ATI, ATE, ATS

Definition

One of the plutonium (all 1sotopes) conversion ratio constants of the three metal types.

Unit

None

Origin

Input data.

\section{$\operatorname{AVIN}(I), \operatorname{AVIN}(B), \operatorname{AVIN}(S), \operatorname{AVIN}(T O T)$}

\section{Definition}

Average incremental cost of plutonium (all isotopes) of three metal types plus the total production incremental cost of the three metal types.

Unit

Dollars per gram. 
Origin

Calculated:

$$
\begin{aligned}
& \text { AVINI }=\frac{\text { BOCI }+ \text { TPCI }}{\text { GRMI }} \\
& \text { AVINE }=\frac{\text { BOCE }+ \text { TPCE }}{\text { GRME }} \\
& \text { AVINS }=\frac{\text { BOC.S }+ \text { TPCS }}{\text { GRMS }} \\
& \text { AVINT }=\frac{\text { BOCT }+ \text { TPCT }}{\text { GRMI }}
\end{aligned}
$$

$\mathrm{B} 24 \mathrm{I}, \mathrm{B} 24 \mathrm{E}, \mathrm{B} 24 \mathrm{~S}$

\section{Definition}

One of the Pu-240 conversion ratio constants of the three metal types.

Unit

None

Origin

Input data.

$\mathrm{BI}, \mathrm{BE}, \mathrm{BS}$

\section{Definition}

The cost of the U-235 isotope burnout per gram of plutonlum produced of the three metal types.

Unit

Dollars per gram

Origin

Input data. 
$\mathrm{BOC}(\mathrm{I}), \mathrm{BOC}(\mathrm{E}), \mathrm{BOC}(\mathrm{S}), \mathrm{BOC}(\mathrm{TOT})$

\section{Definition}

The burnout cost of the three metal types and the total burnout cost of these three metal types.

Unit

Dollars per calendar day.

\section{Origin}

Calculated:

$$
\begin{aligned}
& B O C I=B I(G R M I) \\
& B O C E=B E(G R M E) \\
& B O C S=B S \text { (GRMS) } \\
& B O C T=B O C I+B O C E+B O C S
\end{aligned}
$$

BT

\section{Definition}

The reactor bulk outlet temperature.

Unit

Degree centigrade

Origin

Calculated:

$$
\mathrm{BT}=\mathrm{TIN}+\frac{1000 \cdot(\mathrm{P})(\mathrm{EN})}{.2635(\mathrm{FR})}
$$

NOIE: In the future, (FR) will be replaced with (FR + F8), where FS is the shield flow. 
$\mathrm{BTI}, \mathrm{BTE}, \mathrm{BTS}$

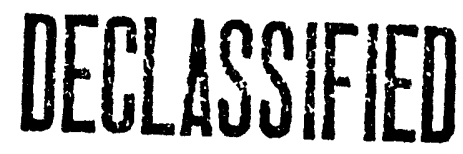

Definition

One of the plutonium (all 1sotopes) conversion ratio constants of the three metal types.

Unit

None

Origin

Input data.

$\mathrm{CD}(I), C D(E), C D(S), C D(T O T)$

Definition

Charge-discharge loss of the three metal types and the total charge-discharge loss of the three metal types.

Unit

Days per calendar day.

Origin

Calculated:

$$
\begin{aligned}
& \mathrm{CDI}=\frac{\mathrm{EYE}(\mathrm{PN})(\mathrm{TTI})(\mathrm{CDINNE})(\mathrm{PE})}{\mathrm{EMI}(\mathrm{CDRI})} \\
& \mathrm{CDE}=\frac{\mathrm{E}(\mathrm{PN})(\mathrm{TTE})(\mathrm{CDIENE})(\mathrm{PE})}{\mathrm{EME}(\mathrm{CDRE})} \\
& \mathrm{CDS}=\frac{\mathrm{S}(\mathrm{PN})(\mathrm{TTS})(\mathrm{CDISNE})(\mathrm{PE})}{\mathrm{EMS}(\mathrm{CDRS})} \\
& \mathrm{CDT}=\mathrm{CDI}+\mathrm{CDE}+\mathrm{CDS}
\end{aligned}
$$

\section{CDLTNE, CDIENS, CDLSNE}

\section{Definition}

The factor for multiplying charge-discharge downtime loss so that non-equilibrium losses will also be represented. 
Unit

None

Origin

\section{DELLLSSFFIED}

Input data.

CDRI, CDRE, CDRS

\section{Defintion}

The charge-discharge rate, including setup and button-up time, of the three metal types.

Unit

Tubes per calendar day.

Origin

Input data.

$\underline{\mathrm{CK}}$

Definition

A factor to adjust the calculated corrosion rates to those representative of the reactor.

Unit

None

Origin

Input data.

\section{$\underline{\text { CKI }}$}

Definition

A tube corrosion factor used by N. R. Miller and which is equal to 0.0008 . 
Unit

None

Origin

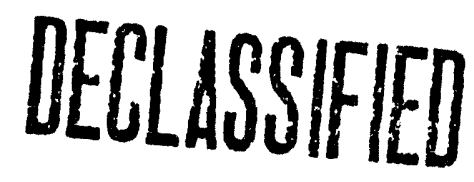

Input data.

\section{CONVRI, CONVRB, CONVRS}

\section{Definition}

The conversion ratio of plutonium (all isotopes) of the three metal types.

Unit

Grams per megawatt-day.

\section{Origin}

Calculated:

$$
\begin{aligned}
& \text { CONVRI }=(\text { ATI }) e^{-B T I(B M I)}+\operatorname{CTI}(\text { EMI })^{2}+\text { DTI } \\
& \text { CONVRE }=(A T B) e^{-B T E(B A B)}+\operatorname{CTE}(B M E)^{2}+D I B \\
& \text { CONVRS }=(\text { ATS }) e^{- \text {BIS }(\text { BMS })+\operatorname{CTS}(\text { EMS })^{2}}+\text { DIS }
\end{aligned}
$$

\section{$\operatorname{CON} 24(\mathrm{I}), \operatorname{CON} 24(\mathrm{E}), \operatorname{coN} 24(\mathrm{~S}), \operatorname{coN} 24(\mathrm{TOT})$}

\section{Definition}

Ratio of Pu-240 gram production to real gram plutonium (all isotopes)

production of the three metal types and the ratio of total Pu-240 grams

to total real grams of the three metal types.

Unit

None

Origin

Calculated:

$$
\operatorname{CON} 24 I=\frac{.01 \text { (EMI) }}{\text { A24I }+ \text { B24I(EMI) }}
$$




$$
\begin{aligned}
& \text { CON24E }=\frac{.01 \text { (BME) }}{A 24 B+B 24 R(B M B)} \\
& \text { CoN24s }=\frac{.01 \text { (274s) }}{1248+B 248(2418)} \\
& \text { CON24T }=\text { GRM24T }
\end{aligned}
$$

\section{CTI, CTE, CTS}

\section{Definition}

One of the plutonium (all 1sotopes) conversion ratio constants of the three metal types.

Unit

None

\section{Or1gin}

Input data.

\section{$\underline{\operatorname{DBT}(90-109)}$}

\section{Definition}

A table of dollar loss per day as a function of the calculated bulk outlet temperature (BT).

The dollar $108 s$ value for each integer bulk outlet temperature from 90-109 C is placed in the DBT table, then each time $\mathrm{z}$ is calculated in the program, the value of $\mathrm{Z}$ will be reduced by the interpolated amount between table positions as a function of the BT calculated for that $z$.

Th1s schedule concept is ideally sulted to a varying loss schedule as a function of the bulk outlet temperature.

To use the schedule concept, both cards 12 and 13 must be submitted for each case in addition to setting $I=2$ and $L 7=2$. 
Unit

Dollars per calendar day.

Origin

Input data.

$\underline{\mathrm{DE}(6-20)}$

Definition

A table of fractions of $\mathrm{z}$ (total control $108 \mathrm{~s}$ in dollars per day) as a function of the calculated heat generated (E) in metal type (2).

Each time $\mathrm{Z}$ is calculated, the value will be reduced by the product of $\mathrm{Z}$ and the fraction in the table corresponding to the truncated $\mathbf{E}$ value calculated for that $\mathbf{z}$.

This schedule may be used as a cut-off or as a varying total control loss schedule.

To use the schedule or cut-off concepts, cards 17 and 18 must be submitted for each case in addition to setting $I=2$ and $I 8=2$.

Unit

None

Origin

Input data.

DM

Definition

The number of days per month. It is customary to use the value 30 . Unit

Days per month. 
Or1gin

Input date.

$\underline{\text { DMR }}$

\section{Definttion}

The number of mils removed from a tube wall before the tube is replaced.

Unit

Mils per tube.

Origin

Input data.

\section{DFE(61-85)}

Definition

A table of dollar $108 s$ per day as a function of the calculated production efficlency (FE).

The dollar loss value for each integer production efficiency value from 61-85 per cent 18 placed in the DFE table, then each time $\mathrm{Z}$ is calculated in the program, the value of $\mathbf{z}$ will be reduced by the amount in the table position corresponding to the truncated $F E$ value calculated for that

z.

Th1s schedule may be used as a cut-off or as a varying loss schedule as a function of the production efficiency.

To use the schedule or cut-off concepts, cards 14, 15, and 16 must be suitritted for each case in audition to setting $I=2, L 9-2$.

Un1t

Dollars per calendar day. 


\section{Origin}

Input data.

DRII $\times 10^{\mathrm{NXI},} \operatorname{DRIS} \times 10^{\mathrm{NXR},}$ DRIS $\times 10^{\mathrm{NDCS}}$

\section{Definttion}

The delta rupture index $(\triangle R I)$ of the three metal types are a measure of the severity of operating conditions as related to ruptures.

$$
\text { Ruptures }=(\Delta R I)(q)
$$

Un1ts

Rupture potential $(\Delta R I)$ per equilibrium day.

Or1g1n

Calculated:

$$
\begin{aligned}
& \text { DRII } \times 10^{N N I}=\operatorname{ELE}(\mathrm{AI})(\mathrm{P})(\mathrm{EN})\left(\frac{\mathrm{TPI}}{\operatorname{MII})}[1000 .(\mathrm{TPI})(\mathrm{P})] \operatorname{XPI}\right.
\end{aligned}
$$

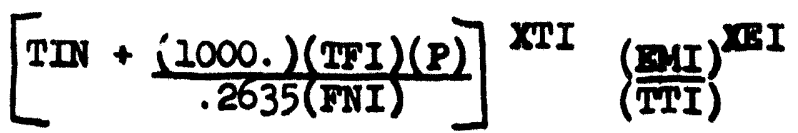

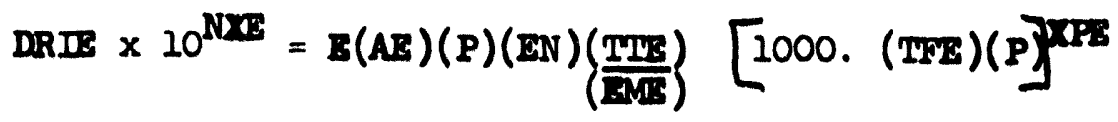

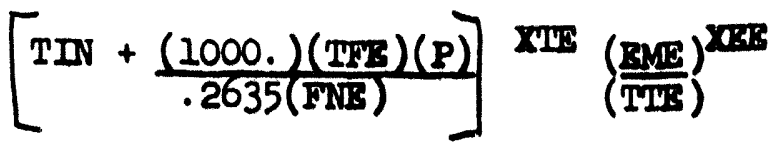

$$
\begin{aligned}
& \text { DRIS } \times 10^{N \times S}=S(\Lambda S)(P)(\text { RN })\left(\frac { \text { TIS } } { ( \text { FNS } ) } \left[1000 \cdot(\text { TFS })(P)^{\text {XPPS }}\right.\right.
\end{aligned}
$$

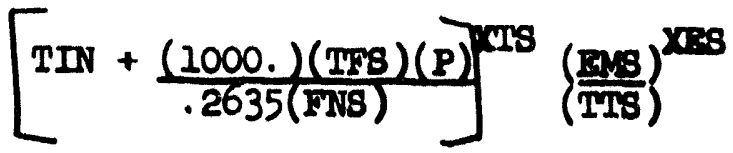

DII, DIE, DIS

Definition

The conversion ratio constant for tritium equivalent grams of plutonium for 
the three metal types. For uon $-\mathrm{Z}-\mathrm{N}$, or non $-\mathrm{N}$ metal types, this value would be zero.

Un1t

Grams per megawatt-day.

Origin

Input data.

DIR

Definition

The tube replacement rate.

Unit

Tubes per calendar day.

Origin

Input data.

$\underline{\mathbf{E}}$

Definition

The fraction of total reactor heat generated in metal type (2). (Formerly, I\&E enriched metal.)

Unit

None

Origin

Calculated:

$$
\begin{aligned}
& R E=\frac{(Q R)(R F)}{A T} \\
& S E=[(Q S)(S F)+(E M B-E M I)(Q M I)(S F)+(P-P B)(E N)(Q P)(S F)] / A T
\end{aligned}
$$




$$
\begin{aligned}
\text { If } \mathrm{SE} & \leq 0, \\
\mathbf{E} & =\mathbf{R E} \\
\text { If } \mathbf{S B} & >0, \\
\mathbf{E} & =\mathbf{R E}+\mathbf{S E}
\end{aligned}
$$

\section{BLN}

\section{Definition}

The hours lost, Including non-equilibrium losses, due to one rupture.

Unit

Hours per rupture.

Origin

Input data.

\section{EMB}

\section{Definition}

The goal exposure of metal type (1) at base condition.

Unit

Megawatt-days per ton.

Origin

Input data.

BMCI, EMCE, BMCS

Definition

Incremental metal cost of the three metal types.

Unit

Dollars per ton. 
Origin

Input data.

DECLLSSFIED

EMI

Definition

The goal exposure of metal group (1).

Unit

Megawatt-days per ton.

Origin

Input data for fixed case, varied for optimum case, schedule for exposure ridge cases $(200-1000, \Delta 100 \mathrm{MN} / \mathrm{T})$, varied for power ridge cases.

EME, EMS

\section{Definition}

Goal exposure of metal groups (2) and (3).

Unit

Megawatt-days per ton.

Origin

Input data for fixed cases, varied for optimum cases, varied for ridge cases.

EMISC

\section{Definition}

Hisccllaneous losses: downtime due to miscellaneous reasons and chargeable to one day's equilibrium operation.

Unit

Days per equilibrium day. 
Origin

Input data.

DECLASSIFIED

EN

Definition

The number of effective central zone tubes (ECT).

Unit

Tubes

Origin

Input data.

EQI $\times 10^{N Q X I}$, EOE $\times 10^{N Q X X}$, EOS $\times 10^{\text {NQXS }}$

Definition

The metal performance level multiplier (q) of the three metal iypes.

Ruptures $=\triangle R I \times q$

Unit

Ruptures per $\triangle R I$.

Origin

Input data.

$\underline{E Y}$

Definition

The fraction of total reactor heat generated in metal type (1). (Formerly, I\&E E).

Unit

None 
Origin

Calculated:

$$
\mathbf{E}=1 \cdot \mathbf{E}-\mathbf{S}
$$

FC

\section{Definition}

The fixed cost per day. These are costs which are considered not to vary significantly with process variables.

Unit

Dollars per calendar day.

\section{Origin}

Input data.

FNI, FNE, FNS

Definition

The average tube flow rate of the three metal types.

Unit

Gallons per minute.

Origin

Input data.

$\underline{\text { FR }}$

\section{Definition}

The reactor flow rate.

NOIE: In the ruture, FR will represent the reactor flow and a new input data quartity, FS (shield flow) will be added to the input dati. Lulk tomp- 
erature (BT) will then be calculated using the bulk flow (FR + FS) and tube corrosion values will be calculated using the reactor flow (FR) only.

Unit

Gallons per minute.

Origin

DEELLSSSFFED

Input data.

GR

\section{Definition}

The ratio of heat generated in an enrichment column to that generated in a natural column, when both are at the same location.

NOIE: The location factor value is programmed to be 1.0 , regardless of the input data value.

Unit

None

Origin

Input data (see note).

$\operatorname{GRM}(I), \operatorname{GRM}(E), \operatorname{GRM}(\mathrm{S}), \operatorname{GRM}(\mathrm{T})$

\section{Definition}

Total production of plutonium (all isotopes) of the three metal types and the grand total production of the three metal types. (Includes tritium equivalent grams (TEGR)).

Unit

Grams per calendar day. 


\section{Origin}

Calculated:

$$
\begin{aligned}
& \text { GRMI }=\text { CONVRI (FMWDI) } \\
& \text { GRME }=\text { CONVRE (FMNDS) } \\
& \text { GRMS }=\text { CONVRS (FMWDS) } \\
& \text { GRMI }=\text { GRMI + GRME + GRMS }
\end{aligned}
$$

\section{DECLLSSFFIED}

$\operatorname{GRM} 4$ (I), GRM24(E), GRM24(S), GRM24(TOT)

\section{Definition}

Production of Pu-240 isotope of the three metal types and the total Pu-240 production of the three metal types.

Unit

Grams per calendar day.

Origin

Calculated:

$$
\begin{aligned}
& \text { GRM24I }=\text { CON24I(RGRI) } \\
& \text { GRM24E }=\text { CON24I (RGRE) } \\
& \text { GRM24S }=\text { CON24S(RGRS) } \\
& \text { GRM24T }=\text { GRM24I + GRM24E + GRM24S }
\end{aligned}
$$

\section{I}

\section{Definition}

The primary control parameter associated with the auxillary loss schedules or optimization cut-off control parameters: L7, L8, L9. If auxiliary loss schedules or cut-off routine is used, set $I=2$. If not, set $I=1$. (Refer to L7, L8, and I9 for further definition of inter-dependence.) 
Unit

None

Origin

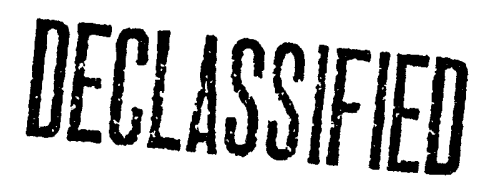

Input data.

$\underline{I}$

Definition

Reactor identification: $B=1, C=2, D=3, D R=4, F=5, H=6, K R=7$, $\mathbf{K N}=8, \mathbf{N}=9$.

Unit

None

Origin

Input data.

I2

Definition

The control parameter for optimum case calculation. If an optimum case is to be calculated from the input data, set $I 2=2$. If not, set $\mathrm{I} 2=0$.

Unit

None

Origin

Input data.

I3

Definition

The control parameter for power and exposure ridge calculations. If ridge cases are to be calculated from the input data, set $\mathbf{L} 3=2$. If not, set $L_{3}=0$. 


\section{Unit}

None

Origin

Input data.

$\underline{14}$

\section{Definition}

The control parameter for fixed case calculations. If fixed case(s) are to be calculated from the input data, set $I_{H}=2$, and submit one card 19 for each case. If not, set If $=0$.

Unit

None

\section{Origin}

Input data.

L7

\section{Definition}

The control parameter indicating the use of the bulk temperature auxiliary loss schedule as a function of BT, or the bulk cut-off' routine. If the auxiliary loss schedule is used, set $I=2, I 7=2$, and submit cards $I 2$ and 13 for each set of input data. If the bulk cut-off routine is used (TB, TBC), set $I=2, L 7=3$. If neither are used, set $L 7=0$.

Unit

None

Origin

Input data. 
됴

Definition

The control parameter indicating the use of the total control auxiliary loss schedule as a function of $\mathrm{F}$. If the auxiliary $108 \mathrm{~s}$ schedule is used, set I $=2$, I $8=2$, and submit cards 17 and 18 for each set of input data. If not, set $18=0$.

Unit

None

Origin

Input data.

I9

Definition

The control parameter indicating the use of the production efficiency auxiliary loss schedule as a function of $\mathrm{FE}$. If the auxiliary loss schedule is used, set $I=2$, $L 9=2$, and submit cards 14,15 , and 16 for each set of input data. If not, set $I 9=0$.

Unit

None

Origin

Input data.

\section{$\mathrm{L} 214$}

\section{Definition}

The control parameter for accumulation of optimum case results. If accumulation is cicired, set $\mathrm{L} / 4=2$. If not, set $\mathrm{L} / 4=0$. INOIE: This part of the program will be removed in the future. 
Unit

None

Origin

Input data.

$\underline{\underline{I} 5}$

Definition

The control parameter for accumulation of fixed case results. If accumulation is desired, set ILI5 $=2$. If' not, set $\mathrm{LI} 5=0$.

NOTE: This part of the program will be removed in the future.

Unit

None

Origin

Input data.

$\underline{120}$

Definition

'ise control parameter used in the summation routine. If a sumnatior is desired, set $120=2$ in CARD A. I20 must be set to 0 (blank) in CARD 1 of the Input daia Group.

Unit

None

Origin

Input dits. 
$N(1-9)$

Definition

The case numbers used in the summation routine. One or more (up to nine) cases can be sumed by placing the case number(8) in positions NI through N9. The total number of cases (NC) must also be included on CARD B.

Unit

None

Origin

Input data.

NC

Definition

The number of cases (NI-N9) to be summed in the sumation routine.

Unit

None

Origin

Input data.

$\underline{\text { OSI }}$

Definition

Operational Severity Index.

Unit

None

Origin

Calculated:

$$
\text { OSI }=[(T F I)(P)]^{X P I}\left[\operatorname{TIN}+\frac{1000 \cdot(T T I)(P)}{100 \cdot(.2635)(F N I)}\right]^{X T I}
$$




\section{Definition}

Average power of the ten highest power tubes.

Unit

Megawatts

Origin

Input data for flxed case, varled for optimum case, schedule for power ridge cases $(1.0-2.0, \Delta 0.1 \mathrm{MW})$, varied for exposure ridge cases.

$\underline{P B}$

\section{Definition}

The average tube power of the ten highest powered tubes at the base condition. Unit

Megawatts

Origin

Input date.

PE

\section{Definition}

Production efficiency: 1.) the ratio of the actual production for any perlod to the production which would have been obtained had the reactor operated the entire period at the maximum power level attained during the period, 2.) the product of time operated and level operated efficiencies. 3.) the ratio of equilibrium day to calendar day,

$P E=1 . /(1 .+$ TUBE REPLACEMENT LOSS + MISC. LOSS + C-D LOSS + RUPTURE LOSS)

\section{Unit}

None

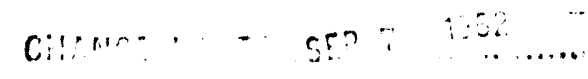




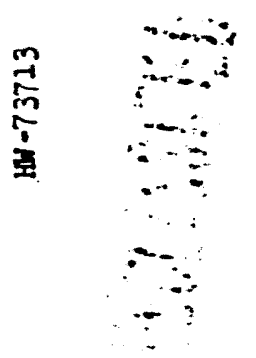

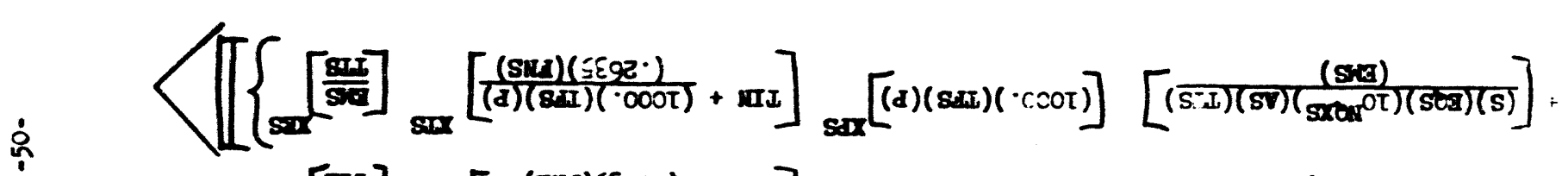

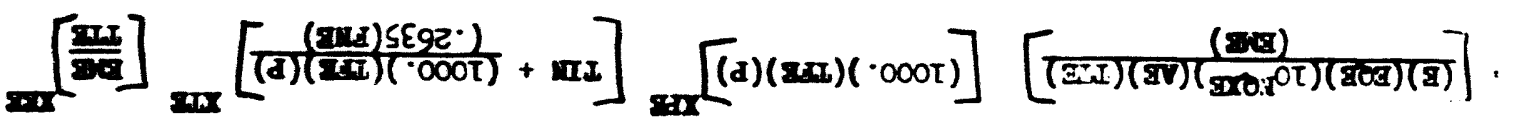

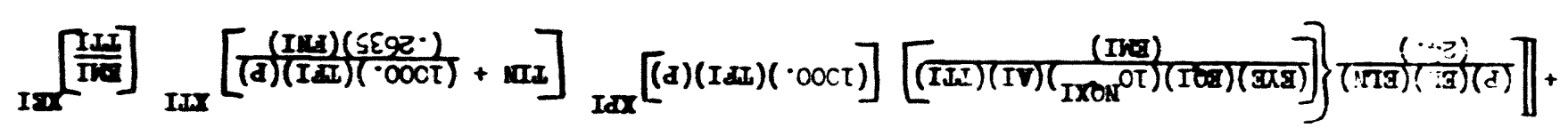

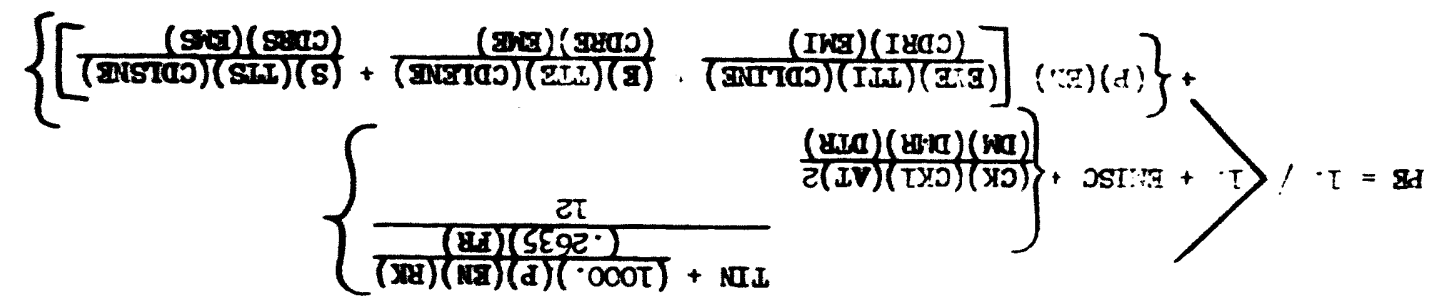

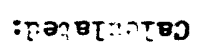

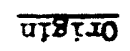


FEMISC

Definition

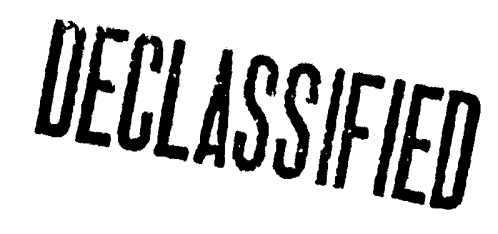

The miscellaneous 1088 term adjusted by the production efficiency.

Unit

Days per calendar day.

Or1gin

Calculated:

$$
\text { FBMISC }=\text { EMISC (PE) }
$$

$\operatorname{PMD}(I), \operatorname{PND}(\mathrm{B}), \mathrm{PND}(\mathrm{S}), \operatorname{BND}(T O T)$

\section{Definition}

The production of the three metal types and the total production of the three metal types.

Unit

Megawatt-days per calendar day.

Origin

Calculated:

$$
\begin{aligned}
& \text { PMWDT }=\text { PN (PE) } \\
& \text { PMWD }=\text { BYE (FMWDT) } \\
& \text { PMWDE }=E \text { ( FMWDT) } \\
& \text { PMWDS }=S \text { (PMWDT) }
\end{aligned}
$$

PN

\section{Definition}

The reactor power level or production for one equilibrium day. 
Un1t

Megawatt, megawatts per equilibrium day.

Origin

Calculated:

$$
P N=(P)(E N)
$$

PU

\section{Definition}

The assigned worth of plutonium.

Unit

Dollars per gram.

Origin

Input data.

\section{QMI}

Definition

The change in number of enrichment (metal type (2)) columns per one MND/T change from the base exposure (EMB).

Unit

Tubes per $M / T$.

Origin

Input data.

$Q P$

Definition

The change in number of enrichment (metal type (2)) columns per one megawatt change from the base tube power (PB). 
Unit

Tubes per megawatt.

Origin

Input data.

QR

Definition

The number of enrichment columns in the flattening ring.

Unit

Tubes

Origin

Input data.

QS

Defintion

The number of enrichment columns used for spike enrichment.

Unit

Tubes

Origin

Input data.

RF

Definition

The average tube factor of the flattening ring columns (QR).

Unit

None 
Origin

Input data.

$\operatorname{RGR}(I), \operatorname{RGR}(\mathrm{B}), \operatorname{RGR}(\mathrm{S}), \operatorname{RGR}(\mathrm{TOT})$

\section{Definition}

The production of real grams of plutontum (all 18otopes) of three metal types and the total production of real grams of the three metal types. (Does not include tritium equivalent grams (WGR)).

Untt

Grams per calendar day.

Origin

Calculated:

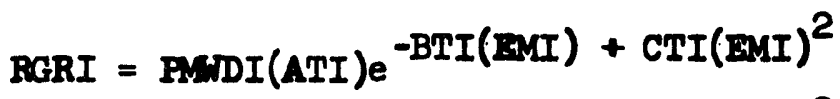

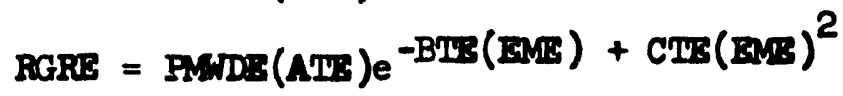

$$
\begin{aligned}
& \text { RGRS }=\operatorname{PMNDS}(\text { ATS }) e^{-B I S(\text { FMS })}+\operatorname{CIS}(\text { MUS })^{2} \\
& \text { RGRT = RGRI + RGRE + RGRS }
\end{aligned}
$$

RK

Defintition

The average ratio of the tube annulus delta temperature to the tube bulk delta temperature.

Unit

None

Origin

Input data. 
$\mathrm{RL}(\mathrm{I}), \mathrm{RL}(\mathrm{E}), \mathrm{RL}(\mathrm{S}), \mathrm{RL}(\mathrm{TOT})$

\section{Definition}

The slug rupture removal time loss of the three metal types and the total rupture removal time loss of the three metal types.

Unit

Days per calendar day.

Origin

Calculated:

$$
\begin{aligned}
& R I I=\operatorname{DRII}(\text { EQI })(10)^{\mathrm{NXI}}+\operatorname{MaXI} \frac{(\mathrm{BIN})}{(24)}(\mathrm{FE}) \\
& \operatorname{RIS}=\operatorname{DRIS}(\operatorname{EDE})(10)^{\mathrm{NDES}}+\operatorname{MOXTE}_{\left.\frac{(E I N)}{(24}\right)}(\mathrm{FE}) \\
& \text { RIS }=\operatorname{DRIS}(\text { BOS })(10)^{\mathrm{NOSS}+\mathrm{NONS}} \frac{(\mathrm{BIN})}{(24)}(\mathrm{FB}) \\
& R I T \text { = RII + RII + RIS }
\end{aligned}
$$

$\underline{\text { RUP }}$

\section{Definition}

The total number of ruptures of the three metal types.

Unit

Ruptures per calendar day.

Origin

Calculated:

$$
\operatorname{RUP}=\frac{\operatorname{RIT}(24)}{\operatorname{ELN}}
$$

$\underline{\mathbf{S}}$

\section{Definition}

The fraction of the total reactor heat generated in metal group (3). 
(Formerly, solld natural metal.)

Unit

None

Origin

Input data.

\section{$\operatorname{SBOC}(I), \operatorname{SBOC}(B), \operatorname{SBOC}(S), \operatorname{SBOC}(T O T)$}

\section{Definition}

The summation of the burnout cost for specifled cases (NI-N9) of three metal types and total burnout cost of the three metal types.

Unit

Dollars per calendar day.

Origin

Calculated:

$$
\begin{aligned}
& \text { SBOCI }=\sum_{1=N 1}^{N 9} \mathrm{BOCI}_{1} \\
& \text { SBOCE }=\sum_{i=N 1}^{N 9} \mathrm{BOCE}_{1} \\
& \text { SBOCS }=\sum_{1=N I}^{N 9} \mathrm{BOCS}_{1} \\
& \text { SBOCT }=\mathrm{SBOCI}+\mathrm{SBOCE}+\mathrm{SBOCS}
\end{aligned}
$$

$\mathrm{sc0} 24(\mathrm{I}), \operatorname{sc0} 24(\mathrm{E}), \operatorname{sco} 44(\mathrm{~S}), \operatorname{sc0} 24$ (TOT)

\section{Definition}

The ratio of the Pu-240 grams summation (BGR24) to the real gram plutonium (all isotopes) summation (SRGR). Does not include tritium equivalent grams (TEGR). 
Unit

None

Origin

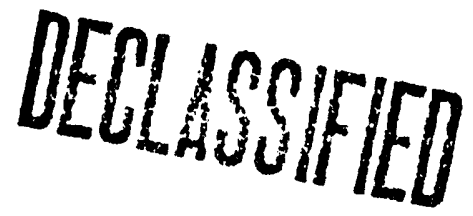

Calculated:

$$
\begin{aligned}
& \text { SCO24I }=\frac{\text { SGR24I }}{\text { SRGRI }} \\
& \text { SC024I }=\frac{\text { SGR24I }}{\text { SRGRE }} \\
& \text { SC024S }=\frac{\text { SGR24S }}{\text { SRGRS }} \\
& \text { SC024T }=\frac{\text { SGR24T }}{\text { SRGRT }}
\end{aligned}
$$

\section{SF}

Definition

The average tube factor of the spike enrichment columns (QS).

Unit

None

Origin

Input data.

SGR24(I), SGR24(E), SGR24(S), SGR24(TOT)

Definition

The summation of Pu-240 isotope grams for specified cases (NI-N9) of three metal types and total Pu-240 grams of the three metal types.

Unit

Grams per calendar day. 
Origin

Calculated:

$$
\begin{aligned}
& \text { SGR24I }=\sum_{1=N 1}^{N 9} \text { GRM24I } \\
& \text { SGR24I }=\sum_{1=N I}^{N 9} \text { GRM24I }_{1} \\
& \text { SGR24S }=\sum_{1=N 1}^{N 9} \text { GRM24S }_{1} \\
& \text { SGR24T }=\text { SGR24I + SGR24E+ SGR24S }
\end{aligned}
$$

\section{$\operatorname{SGRM}(I), \operatorname{SGRM}(E), \operatorname{SGRM}(S), \operatorname{SGRM}(T O T)$}

\section{Definition}

The summation of total grams (GRM) for specified cases (NI-N9) of three metal types and total grams of the three metal types. Includes tritium equivalent grams (TEGR).

Unit

Grams per calendar day.

Origin

Calculated:

$$
\begin{aligned}
& \text { SGRMI }=\sum_{i=N I}^{N 9} \text { GRMI }_{i} \\
& \text { SGRME }=\sum_{i=N I}^{N 9} \text { GRME }_{i} \\
& \text { SGRMS }=\sum_{1=N I}^{N 9} \text { GRMS }_{i} \\
& \text { SGRMI }=\text { SGRMI + SGRME + SGRMS }
\end{aligned}
$$


$\operatorname{SRGR}(I), \operatorname{SRGR}(E), \operatorname{SRGR}(S), \operatorname{SRGR}(T O T)$

Definition

The summation of real grams (RGR) for specified cases (NI-N9) of three metal

types and total real grams of the three metal types. Does not include tritium equivalent grams (TEGR).

Unit

Grams per calendar day.

Origin

Calculated:

$$
\begin{aligned}
& \text { SRGRI }=\sum_{i=N 1}^{N 9} \text { RGRI }_{1} \\
& \text { SRGRI }=\sum_{i=N I}^{N 9} \text { RGRE }_{i} \\
& \text { SRGRS }=\sum_{i=N I}^{N 9} \text { RGRS }_{i} \\
& \text { SRGRT }=\text { SRGRI + SRGRE + SRGRS }
\end{aligned}
$$

\section{$\operatorname{STEGR}(I), \operatorname{STEGR}(E), \operatorname{STEGR}(\mathrm{S}), \operatorname{STEGR}(T O T)$}

\section{Definition}

The summation of tritium equivalent grams (TEGR) for specified cases (NI-N9)

of three metal types and total tritium equivalent grams of the three metal types.

Unit

Grams per calendar day.

Origin

Calculated: 


$$
\begin{aligned}
& \text { STEGRI }=\sum_{1=N 1}^{N 9} \text { TEGRI }_{1} \\
& \text { STEGRI }=\sum_{i=N 1}^{N 9} \text { TEGRS }_{1} \\
& \text { STEGRS }=\sum_{1=N 1}^{N 9} \text { TIERS }_{1} \\
& \text { STEGRT }=\text { STMGRI + STEGRE + STEGRS }
\end{aligned}
$$

\section{$\operatorname{STP}(I), \operatorname{STP}(E), \operatorname{STP}(S), \operatorname{STP}(T O T)$}

\section{Definition}

The summation of the metal tilroughput for specified cases (N1-N9) of three metal types and total throughput of the three metal types.

Unit

Tons per calendar day.

Origin

Calculated:

$$
\begin{aligned}
& \text { STPI }=\sum_{i=N 1}^{N 9} \mathrm{TPI}_{i} \\
& \text { STPE }=\sum_{i=N 1}^{N 9} \mathrm{TPE}_{i} \\
& \text { STPS }=\sum_{i=N 1}^{N 9} \text { TPS }_{1} \\
& \text { STPT }=\text { STPI + STPE + STPS }
\end{aligned}
$$

$\operatorname{STPC}(I), \operatorname{STPC}(B), \operatorname{STPC}(\mathrm{S}), \operatorname{STPC}(\operatorname{TOT})$

\section{Definition}

The summation of the metal throughput cost for specified cases (NI-N9) of 
three metal types and total throughput cost of the three metal types.

Unit

Dollars per calendar day.

Origin

Calculated:

$$
\begin{aligned}
& \text { STPCI }=\sum_{1=N I}^{N 9} \operatorname{TPCI}_{1} \\
& \text { STPCE }=\sum_{1=N I}^{N 9} \operatorname{TPCB}_{1} \\
& \text { STPCS }=\sum_{1=N 1}^{N 9} \text { TPCS }_{1} \\
& \text { STPCT }=\text { STPCI + STPCE + STPCS }
\end{aligned}
$$

TB

\section{Definition}

The bulk temperature cut-off limlt. By setting $I=2, I 7=3$, the power (P) will not exceed the TB limit.

Unit

Degrees centigrade.

Origin

Input data.

\section{TBC}

\section{Definition}

The bulk temperature cut-off limtt (TB) dollars required to assure the power (P) will not exceed the TB limit. Normally, this value is $\$ 10,000$. 
$\underline{\text { Unit }}$

Dollars

Origin

Input data.

$\operatorname{TEGR}(I), \operatorname{TEGR}(E), \operatorname{TEGR}(\mathrm{S}), \operatorname{TEGR}(\mathrm{TOT})$

Definition

The production of tritium equivalent grams ( $\mathrm{E}-\mathrm{N}$, N load) of three metal types and the total tritium equivalent grams of the three metal types.

Unit

Grams per calendar day.

Origin

Calculated:

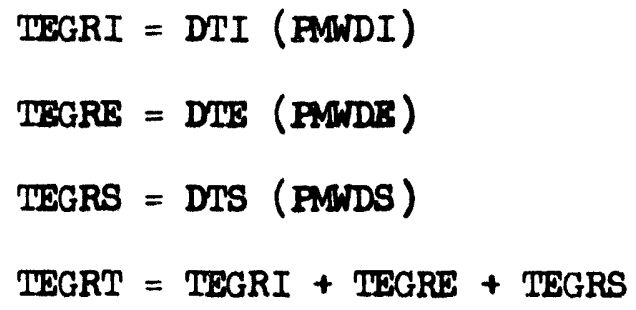

TFI, TFE, TFS

Definition

The rupture model power distribution factor of the three metal eroups Norrally, this value is 1.0 .

Unit

None

Origin

Input data. 
TIN

\section{Defindtion}

The process water bulk inlet temperature.

Unit

Degrees cent1grade.

Origin

Input data.

$\operatorname{TP}(I), \operatorname{TP}(B), \operatorname{TP}(8), \operatorname{TP}(\operatorname{TOT})$

The metal throughput of the three metal types and the total metal throughput of the three metal types.

Unit

Tons per calendar day.

Calculated:

$$
\begin{aligned}
& \text { TPI }=\frac{\text { PMNI }}{\text { BMI }} \\
& \text { TPE }=\frac{\text { PMNDS }}{\text { EME }} \\
& \text { TPS }=\frac{\text { PMNDS }}{\text { EMS }} \\
& \text { TPT }=\text { TPI + TPE + TPS }
\end{aligned}
$$

$\operatorname{TPC}(I), \operatorname{TPC}(\mathrm{E}), \operatorname{TPC}(\mathrm{S}), \operatorname{TPC}(\mathrm{TOT})$

Definition

The throughput cost of the three metal types and the total throughput cost of the three metal types.

Unit

Dollars per calendar day. 
Origin

Calculated:

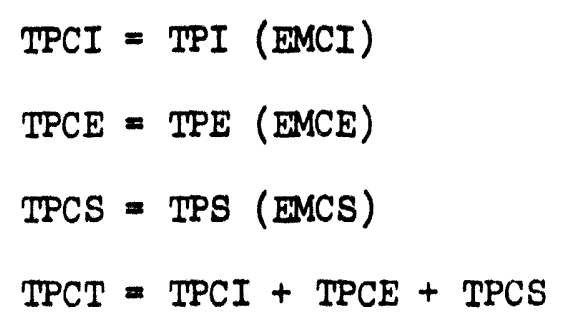

TRL

Definition

The tube replacement 108 s for power dependent tube corrosion.

Unit

Days per calendar day.

Origin

Calculated:

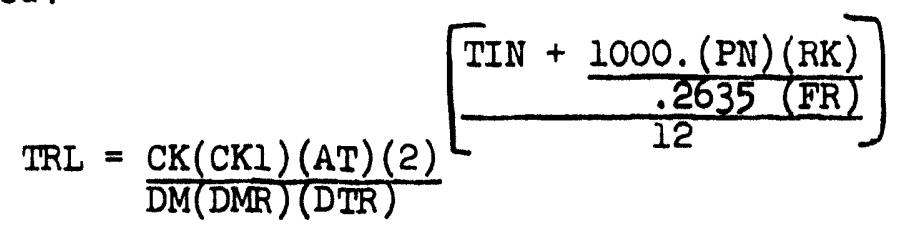

TTI, TTE, TTS

Definition

The numbers of tubes whose bare slug weight totals one ton of the three metal types.

Unit

Tubes per ton.

Origin

Input data. 
UCNR

Definition

Unit cost net return.

Unit

Dollars per gram.

Origin

Calculated:

$$
U C N R=\frac{F g+B O C T+T P C T}{G R M T}
$$

\section{IEI, XFE, XRS}

\section{Definition}

The rupture model exposure exponents of the three metal types.

Unit

None

Origin

Input data.

XPI, XPE, XPS

Definition

The rupture model power exponents of the three metal types.

Unit

None

Origin

Input data. 
XTI, XTE, XTS

Definition

The rupture model tube outlet temperature exponents of the three metal types.

Unit

None

Origin

Input data.

ZSELI

Definition

Net return plus fixed costs for plutonium worth $\$ 50$ per gram.

Unit

Dollars per calendar day.

Origin

Calculated:

$$
\text { ZSELI }=[\text { RGRT (50.) }]-\text { BOCT-TPCT }
$$

$\underline{z}$

Definition

Net return plus fixed cost.

Unit

Dollars per calendar day.

Origin

Calculated:

$$
\begin{aligned}
Z=(P)(E N)(P E) \quad & \left\{E Y E\left[(P U-B I)(C O N V R I)-\frac{E M C I}{E M I}\right]\right. \\
& +E\left[(P U-B E)(C O N V R E)-\frac{E M C E}{E M E}\right] \\
& \left.+S\left[(P U-B S)(C O N V R S)-\frac{E M C S}{E M S}\right]\right\}
\end{aligned}
$$



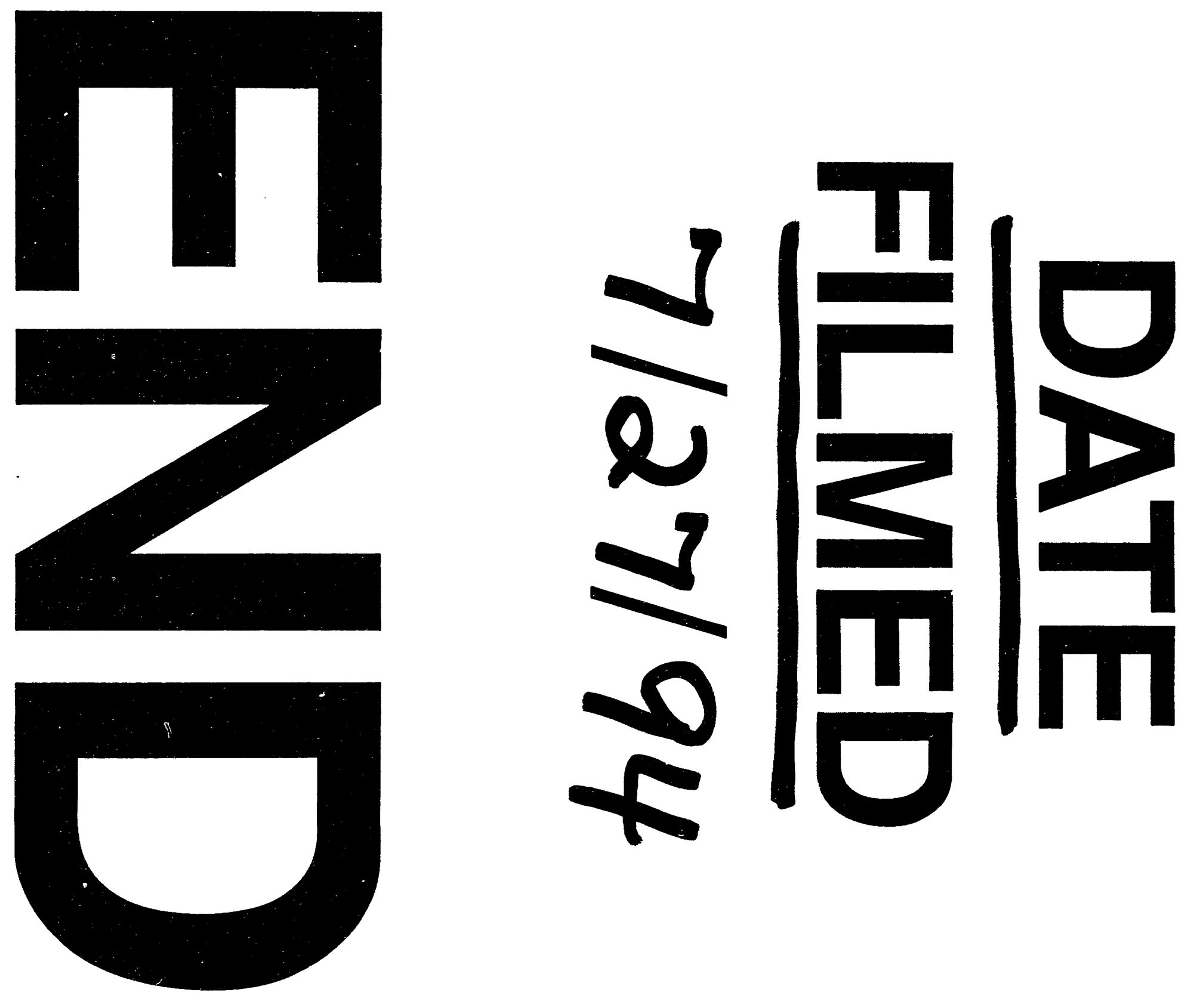
